\title{
Damage mechanisms in cementitious coatings on steel members in bending
}

1 Suwen Chen MSc, PhD

Associate Professor, State Key Laboratory for Disaster Reduction in Civil Engineering, Shanghai, People's Republic of China; also Associate Professor, College of Civil Engineering, Tongji University, Shanghai, People's Republic of China

2. Liming Jiang MSC

Master, College of Civil Engineering, Tongji University, Shanghai, China; and PhD student, School of Engineering, The University of Edinburgh, Edinburgh, UK
3 Asif Usmani MS, PhD, MIStructE, CEng Professor, School of Engineering, The University of Edinburgh, Edinburgh, UK

4 Guo-Qiang Li MSc, PhD

Professor, State Key Laboratory for Disaster Reduction in Civil Engineering, Shanghai, People's Republic of China; also Professor, College of Civil Engineering, Tongji University, Shanghai, People's Republic of China
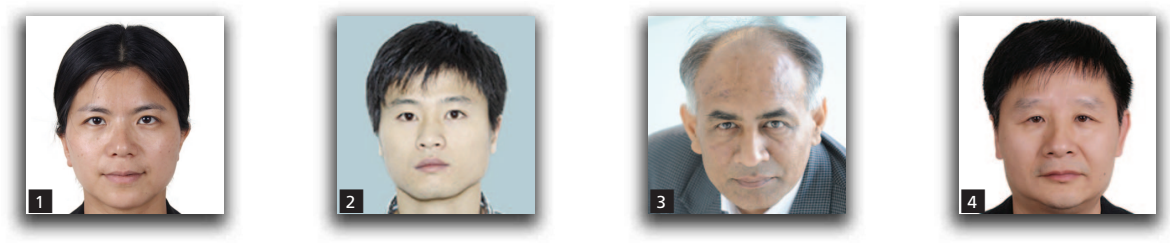

Cementitious coatings are widely used as fire protection for steel structures but they are vulnerable to damage from structural deformations. In this paper, damage mechanisms in cementitious coatings on steel members in bending are investigated. A series of monotonically loaded beam tests are conducted to observe the occurrence of cracks and their propagation leading to final failure. The experiments are then simulated using a cohesive zone finite-element scheme, capable of modelling interfacial damage between the coating and steel substrate as well as internal coating damage. The results of the experimental and numerical studies clearly reveal the distinct damage mechanisms of cementitious coatings on both tension and compression sides of structural steel members in bending. Findings from this study provide the foundation for developing practical methods to determine the condition of cementitious coatings on steel structures after a short-duration extreme loading event (earthquake, blast, windstorms), where there is minimal external damage to the building fabric or longduration cumulative damage from moderate levels of repeated non-monotonic loading. It is very unlikely in either of these cases that the integrity of cementitious fire protective coatings has been investigated in current practice.

\section{Notation}

$d_{\alpha} \quad$ damage parameter

$d_{\mathrm{m}} \quad$ mixed-mode damage parameter

$E_{\mathrm{c}} \quad$ elastic modulus of coating

$E_{\mathrm{s}} \quad$ elastic modulus of steel

$G_{\mathrm{C}} \quad$ shear modulus of coating

$G_{\mathrm{cn}}, G_{\mathrm{ct}} \quad$ critical fracture energies in normal and tangential directions, respectively

$G_{\mathrm{n}}, G_{\mathrm{t}} \quad$ fracture energies in normal and tangential directions, respectively

$G_{\mathrm{S}} \quad$ shear modulus of steel

$h_{\mathrm{c}} \quad$ thickness of coating

$h_{\mathrm{s}} \quad$ thickness of steel plate

$I_{\mathrm{c}} \quad$ inertia moment of coating section

$I_{\mathrm{s}} \quad$ inertia moment of steel section

$K_{\alpha} \quad$ initial penalty stiffness parameter length of coating

axial force

traction (subscript $\alpha$ can be 'n' or 't' referring to normal and tangential directions)

critical relative displacement

elastic relative displacement

relative displacement

maximum value of relative displacement in loading history

a ratio parameter

Poisson's ratio of coating

Poisson's ratio of steel

tangential interlaminar stress

stiffness degradation factor due to interfacial

damage in single-mode delamination 
$\phi_{\mathrm{m}}$

stiffness degradation factor due to interfacial damage in mixed-mode delamination

$\phi_{\mathrm{f}}$ curvature of neutral plane of steel plate

\section{Introduction}

Cementitious fire-resistant coating is one of the most widely used fire protection methods for steel structures because of its many advantages, such as low density, low thermal conductivity (around $0 \cdot 1 \mathrm{~W} / \mathrm{m} \mathrm{K}$ ), low cost and non-toxic emissions in fire. The coating is expected to remain effective for many years even though its actual condition is unknown, given that it is usually hidden behind architectural decoration and finishes because of its aesthetically undesirable appearance. During its lifetime, a building structure may be exposed to significant deformations from severe loadings, such as high winds or seismic action. If there are minimal external signs of damage, as is possible in a well-designed structure, it would normally be assumed that the fireproof coating is also in good condition. Furthermore, an invasive and comprehensive inspection in a functioning building would be inconvenient and expensive. However, cementitious fireproof coating has very low strength and ductility, and is therefore prone to damage (Braxtan and Pessiki, 2011; Jin, 2011; Tan et al., 2011), potentially leading to significant reduction in fire resistance of the protected member (Keller and Pessiki, 2012; Milke et al., 2003; Ryder et al., 2002; Wang and Li, 2009). To determine the actual level of passive fire protection in a building in the aftermath of a high magnitude of loading (or after a relatively long period of moderate magnitudes of repeated nonmonotonic loading), it is very important to understand the performance and damage mechanisms of cementitious coatings and to develop methodologies to determine the in situ condition of cementitious coatings under such loadings.

There is very little research that has addressed this issue so far. Among the available research are studies on adhesive/cohesive strengths of spray-applied fire-resistive materials (SFRM) investigated by Braxtan and Pessiki (2011) and Tan et al. (2011) after the 11 September 2001 terrorist attacks. Dwaikat and Kodur (2011) presented a two-dimensional numerical study to investigate fracture and delamination of SFRM on insulated steel plates subjected to static and impact loads, and have provided several qualitative conclusions from the parametric studies, but these need verification by experimentation.

In order to establish a method to evaluate the damage in cementitious coatings on protected steel members subjected to external loading, fundamental research has been carried out at Tongji University. This includes experiments on the mechanical properties of cementitious materials under ambient temperature (Chen et al., 2010, Jin, 2011), interlaminar stress analysis on axially and flexurally loaded steel members (Chen et al., 2010; Jin, 2011; Wang, 2008), monotonic loading tests on members under axial loads and under pure bending (Chen et al., 2010, 2012a; Jin, 2011, Jiang, 2012), and detailed numerical studies (Chen et al., 2012a, 2012b, Jiang, 2012). In the numerical simulation, a cohesive zone finite-element (CZFE) scheme em- ploying a cohesive zone model (CZM) approach (Alfano and Crisfield, 2001; Turon et al., 2007) for the interfacial crack propagation and the William-Warnke model (William, 1974), for the damage within the coating, are adopted.

The authors' complementary research on the damage mechanisms of cementitious coatings in axially loaded steel members has been extensively reported earlier (Chen et al., 2010, 2012a, 2012b; Jiang, 2012). The key findings from this work were: in coatings under tensile loading, the damage begins with interfacial cracks at both ends, followed by transverse cracks within the coating resulting in its ultimate fracturing into multiple segments; under compressive loading, the damage also initiates at the ends with interfacial cracks and propagates towards the centre until the coating peels off completely. The bulk of this paper is intended to be a continuation of that work and presents a description of experimental and numerical studies carried out to investigate the damage mechanisms in cementitious coatings when steel structural members are under pure bending. A series of monotonically loaded beam tests is performed to investigate the damage on coated steel plates in pure bending. This is followed by numerical simulation and parametric analysis using a CZFE scheme. The experimental and numerical studies reveal consistent damage mechanisms in the cementitious coating on the steel plate in bending. It is hoped that this work will provide a basis for developing robust methodologies to determine the in situ condition of cementitious fireproof coatings as a consequence of real structural deformations under the action of severe loads.

\section{Monotonically loaded beam bending tests}

\subsection{Specimens and measurements}

Pure bending loads are applied on the cementitious material coated steel members to investigate the correlation of damage in the coating with the strains and curvatures in the steel members. To ensure that the insulated plate is in pure bending and to avoid more complex stress states, the test set-up is designed as shown in Figures 1(a) and 1(b), where the insulated length $L$ is $500 \mathrm{~mm}$, the width $W$ is $60 \mathrm{~mm}$ and the thickness $T$ is $20 \mathrm{~mm}$. The specimens tested are listed in Table 1. All the steel plates in tests are of the same size of $800 \mathrm{~mm} \times 100 \mathrm{~mm} \times 20 \mathrm{~mm}$, as shown in Figure 1(a). The measurements include central deflection and strains on top and bottom surfaces of steel plate. Because the glues used for installing strain gauges significantly affect the coating's stiffness and strength, only two specimens have been installed with strain gauges on the coatings. The installation of strain gauges is shown in Figure 1(c) and Figure 1(d).

\subsection{Observation from the tests}

For the case of the 20-mm-thick coating, when the curvature in the neutral plane reaches $0.67 \times 10^{-4} \mathrm{~mm}^{-1}$, interfacial cracks (number 1 in Figures 2(b) and 2(c)) are observed at both ends on the compression side and are observed to propagate towards the centre. When the curvature reaches $0.91 \times 10^{-4} \mathrm{~mm}^{-1}$, the first transverse 

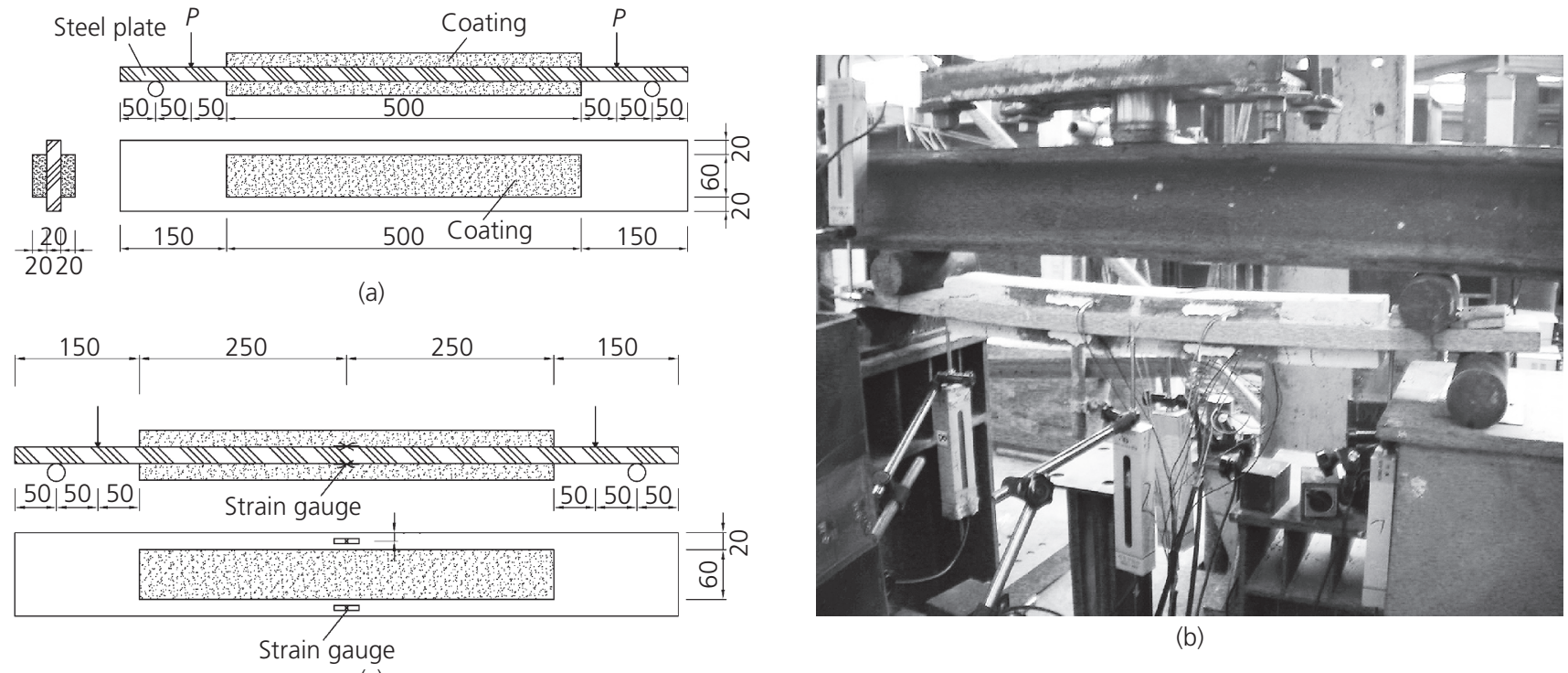

(b)
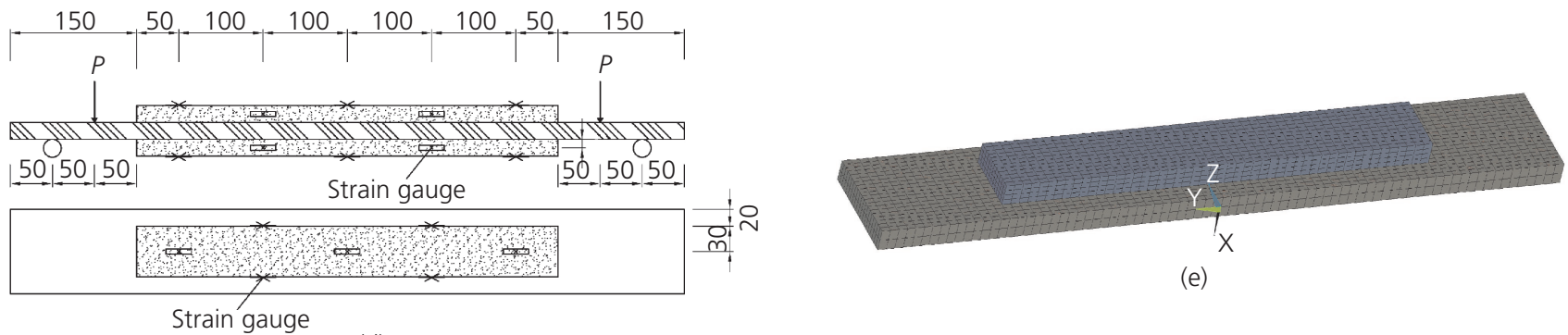

(e)

(d)

Figure 1. Set-up of beam test and finite-element model: (a) dimension of specimen; (b) photo of beam test; (c) strain gauge on steel; (d) strain gauge on coating; (e) finite-element model

\begin{tabular}{|c|c|c|c|c|c|c|c|}
\hline Specimen & CW1-1 & CW1-2 & CW1-3 & CW1-4 & CW2-1 & CW2-2 & CW2-3 \\
\hline Strain gauge on coating & No & No & Yes & No & Yes & No & No \\
\hline Size $(L \times W \times T): \mathrm{mm}^{3}$ & \multicolumn{4}{|c|}{$500 \times 60 \times 20$} & \multicolumn{3}{|c|}{$500 \times 60 \times 30$} \\
\hline $\begin{array}{l}\text { Curvature for first interfacial crack on } \\
\text { compression side: } \times 10^{-4} \mathrm{~mm}^{-1}\end{array}$ & 0.67 & 0.61 & 0.54 & 0.68 & 0.22 & - & $0 \cdot 31$ \\
\hline $\begin{array}{l}\text { Curvature for first transverse crack } \\
\text { on tension side: } \times 10^{-4} \mathrm{~mm}^{-1}\end{array}$ & 0.91 & 0.94 & 0.65 & - & 0.33 & 0.47 & 0.40 \\
\hline
\end{tabular}

Note: '- ' indicates no valid observation.

Table 1. Specimens and test results

crack (number 2 in Figure 2(a)) occurs on the tension side. With further increase in loading, more transverse cracks occur on the tension side (numbers 3-6 and 10, shown in Figures 2(a) and 2(c)) and shear induced fracturing (number 7 shown in Figures 2(b) and 2(c)) on the compression side are observed. The reason for shear fracture on the compression side is the effect of curvature, which induces shear and bending stresses in the delaminated parts of the coating by uplifting the ends. The observed final failure mode is that the coating on the tension side fractures into several segments, and the coating on the compression side delaminates from the steel and fractures due to the effect of curvature.

For the case of 30-mm-thick coating (shown in Figures 2(d)2(f)), a similar phenomenon is observed except that no shear 


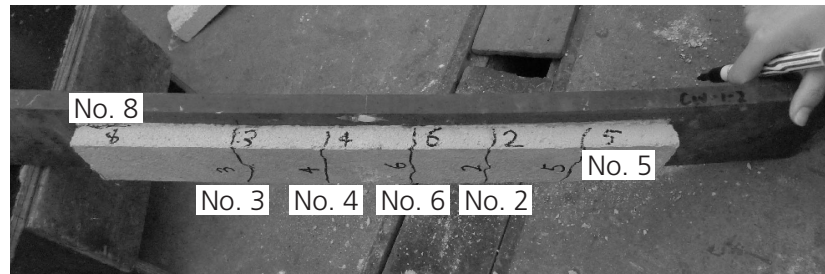

(a)

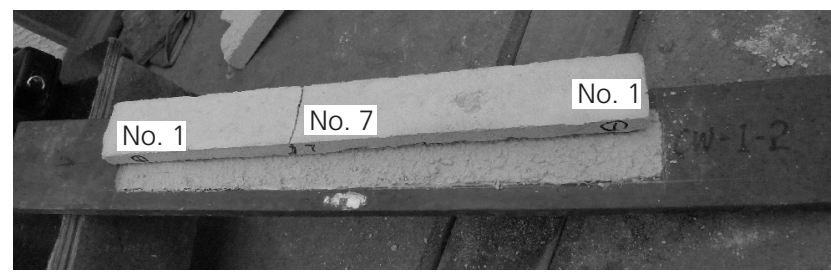

(b)

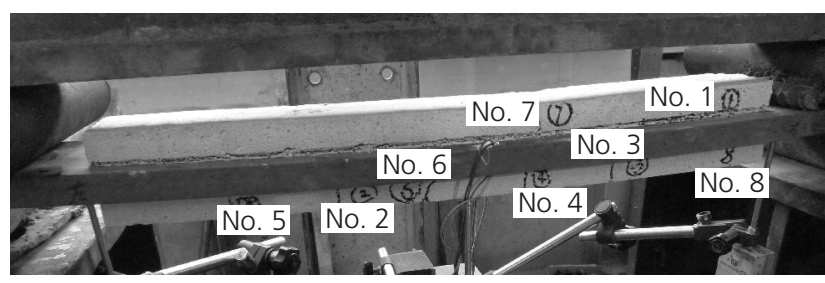

(c)

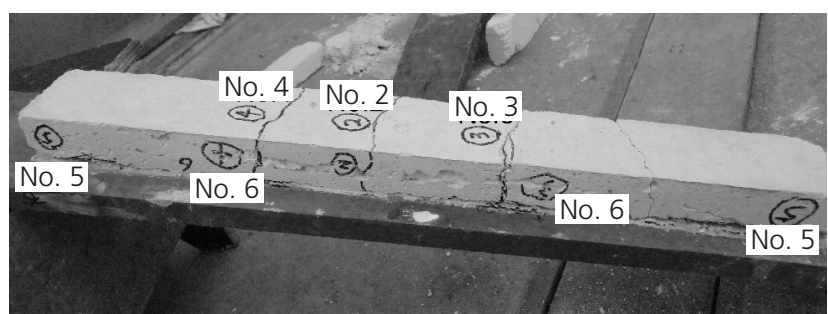

(d)

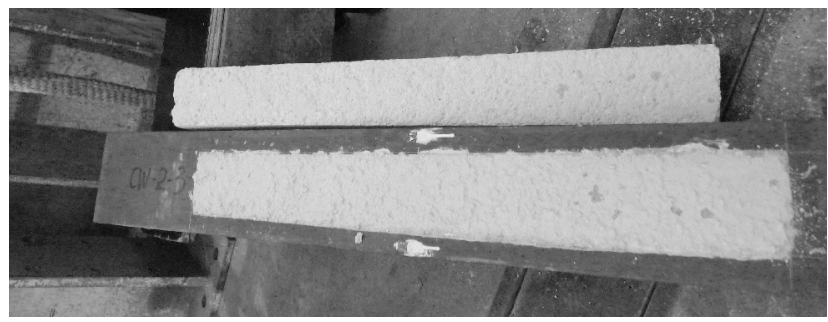

(e)

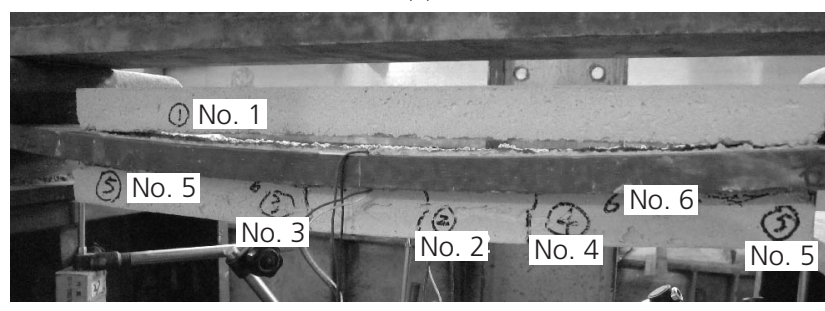

(f)

Figure 2. Failure modes of specimens: (a) fracture of coating on tension side of CW1-2; (b) shear fracture on compression side of CW1-2; (c) failure mode of CW1-2; (d) fracture of coating on tension side of CW2-3; (e) peeling off of the coating on compression side of CW2-3; (f) failure mode of CW2-3 fracture on the compression side is observed and cracks initiate earlier. The curvatures for the first interfacial crack and first transverse crack are about $0.2 \sim 0.3 \times 10^{-4} \mathrm{~mm}^{-1}$ and $0.3 \sim 0.4 \times 10^{-4} \mathrm{~mm}^{-1}$ respectively. The thicker coating causes higher bond stresses and induces earlier occurrence of damage and more severe interfacial damage.

Curvatures corresponding to the first interfacial crack and the first transverse crack of all the specimens are compared in Table 1. Another interesting fact is that cracks occur earlier with strain gauges glued on the coating, as shown by the specimens CW1-3 and CW2-1 listed in Table 1. The glue used for strain gauges seems to increase the stiffness of the coating, resulting in higher interfacial stress and earlier cracking.

\subsection{Conclusions from the tests}

From the monotonically loaded beam bending tests, the following damage mechanisms in the cementitious coating on steel members in pure bending are observed.

(a) For the case of 20-mm-thick coating, interfacial cracks initiate from both ends on the compression side when the curvature in the neutral plane reaches around $0.6 \times 10^{-4} \mathrm{~mm}^{-1}$ and propagate towards the centre, followed by the occurrence of transverse cracks on the tension side. The thicker the coating is, the earlier the cracks occur.

(b) The final failure mode is that the coating on the tension side fractures into several segments and the coating on the compression side peels off. In thinner coatings shear fractures may occur at ends on the compression side due to the effect of uplifting of the ends because of the curvature.

\section{Numerical simulation}

\subsection{Cohesive zone model}

From the experiments, two types of damage in cementitious coatings are observed, $(a)$ mechanical damage within the coating; and $(b)$ interfacial cracking between the coating and steel substrate. Thus, the modelling should be able to describe the formation and propagation of both types of damage.

For handling interface problems in numerical analysis, there are several approaches, such as contact analysis using zero-length spring elements, or directly coupling nodal displacement. Zerolength spring elements are commonly used for simulating singlemode interfacial behaviour in composite members, but it is difficult to resolve the damage state of the interface for different directions without addressing mixed-mode delamination. Directly coupling the nodal displacements at the interface can be used for analysing interfacial (bond) stress in the coating element next to the steel in the elastic regime, but it is not able to model the occurrence and development of interfacial cracking.

In this paper, a CZFE scheme is adopted for simulating the coating and steel substrate interfacial damage, in which a CZM in conjunc- 


\section{Offprint provided courtesy of www.icevirtuallibrary.com Author copy for personal use, not for distribution}

tion with contact pair (Conta173 and Target 171 in Ansys) is employed. In the CZFE approach, the interface is modelled with zero-length (initial state) elements. The constitutive law of the interface is the relationship between interface tractions and relative displacements. When the cohesive zone element is subjected to pure normal or shear stress (usually referred to as 'single-mode delamination'), the constitutive relationship between traction $\left(t_{\alpha}\right)$ and relative displacement $\left(\delta_{\alpha}\right)$ has a general expression as below in Equation 1, in which the subscript $\alpha$ can be ' $n$ ' or ' $t$ ', referring to normal and tangential directions, respectively.

$$
\text { 1. } t_{\alpha}=t_{\alpha}\left(\delta_{\alpha}\right)
$$

For the uncoupled model, two bilinear one-dimensional relationships can be assumed for the normal $(\alpha=n)$ and the tangential $(\alpha=\mathrm{t}$ ) direction respectively, as shown in Figure 3 (Alfano and Crisfield, 2001).

The constitutive law corresponding to Figure 3 can be expressed from a damage mechanics perspective as

2. $t_{\alpha}=\phi_{\alpha} K_{\alpha} \delta_{\alpha}=\left(1-d_{\alpha}\right) K_{\alpha} \delta_{\alpha}$

where $K_{\alpha}$ is the initial penalty stiffness parameter, and a factor

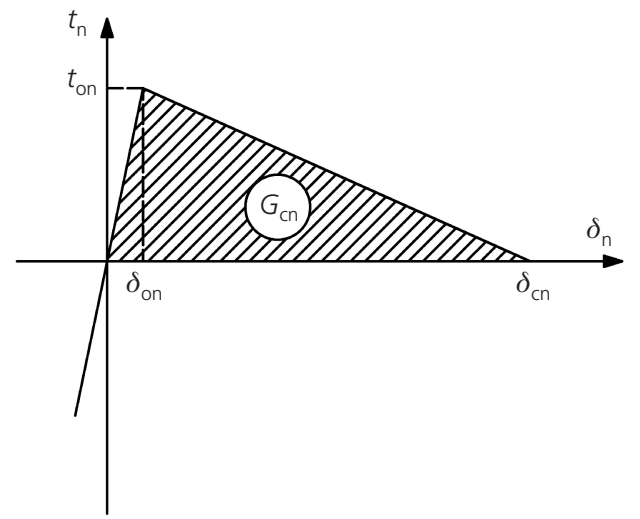

(a)

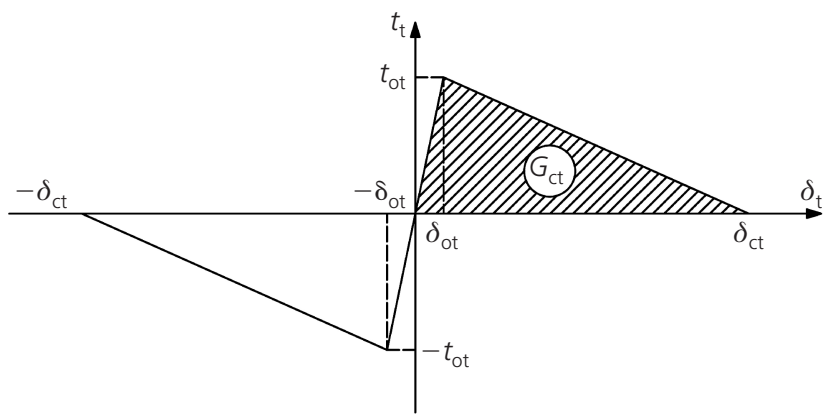

(b)

Figure 3. Uncoupled constitutive relationships: (a) normal direction; (b) tangential direction $\phi_{\alpha}$ is applied to describe the stiffness degradation due to interfacial damage. Correspondingly damage parameter $d_{\alpha}$ is defined by Equation 3. A zero value of $d_{\alpha}$ represents the undamaged elastic interface, while $d_{\alpha}=1$ indicates that the interface is fully damaged.

3. $d_{\alpha}= \begin{cases}0 & \text { if }\left(\delta_{\alpha}^{*} \leqslant \delta_{\mathrm{o} \alpha}\right) \\ \left(\frac{\delta_{\alpha}^{*}-\delta_{\mathrm{o} \alpha}}{\delta_{\alpha}^{*}}\right)\left(\frac{\delta_{\mathrm{c} \alpha}}{\delta_{\mathrm{c} \alpha}-\delta_{\mathrm{o} \alpha}}\right) & \text { if }\left(\delta_{\mathrm{o} \alpha}<\delta_{\alpha}^{*}<\delta_{\mathrm{c} \alpha}\right) \\ 1 & \text { if }\left(\delta_{\alpha}^{*} \geqslant \delta_{\mathrm{c} \alpha}\right)\end{cases}$

where, $\delta_{\mathrm{o} \alpha}$ and $\delta_{\mathrm{c} \alpha}$ are the elastic and critical relative displacements, and $\delta_{\alpha}^{*}$ is the maximum value of the relative displacement in the loading history $\left(0 \leqslant \tau^{\prime} \leqslant \tau\right)$ as shown in Equation 4

$$
\begin{aligned}
& \left\{\begin{array}{l}
\delta_{\mathrm{n}}^{*}=\max _{0 \leqslant \tau^{\prime} \leqslant \tau}\left(\left\langle\delta_{\mathrm{n}}\left(\tau^{\prime}\right)\right\rangle\right) \\
\delta_{\mathrm{t}}^{*}=\max _{0 \leqslant \tau^{\prime} \leqslant \tau}\left(\left|\delta_{\mathrm{t}}\left(\tau^{\prime}\right)\right|\right)
\end{array}\right. \\
& \text { with }\left\langle\delta_{\mathrm{n}}\left(\tau^{\prime}\right)\right\rangle= \begin{cases}0 & \text { if } \delta_{\mathrm{n}}\left(\tau^{\prime}\right)<0 \\
\delta_{\mathrm{n}}\left(\tau^{\prime}\right) & \text { if } \delta_{\mathrm{n}}\left(\tau^{\prime}\right) \geqslant 0\end{cases}
\end{aligned}
$$

Since a proper simulation of debonding should consider both the opening mode and the sliding mode, a modified mixed-mode constitutive relationship is presented by Alfano and Crisfield (2001). They set the ratio of relative displacement in the elastic regime to that in the softening regime to be equal for both the normal and tangential directions.

5. $\quad \eta=1-\frac{\delta_{\mathrm{on}}}{\delta_{\mathrm{cn}}}=1-\frac{\delta_{\mathrm{ot}}}{\delta_{\mathrm{ct}}}$

Then a mixed-mode damage parameter $d_{\mathrm{m}}$ could be introduced on the basis of the ratio parameter $\eta$.

6.

$$
d_{\mathrm{m}}=\max \left[1, \frac{1}{\eta}\left(\frac{\Delta_{\mathrm{m}}^{*}-1}{\Delta_{\mathrm{m}}^{*}}\right)\right]
$$

where $\Delta_{\mathrm{m}}^{*}$ is calculated as below

$$
\begin{aligned}
\Delta_{\mathrm{m}}^{*} & =\max _{0 \leqslant \tau^{\prime} \leqslant \tau}\left[\sqrt{\Delta_{\mathrm{n}}^{2}\left(\tau^{\prime}\right)+\Delta_{\mathrm{t}}^{2}\left(\tau^{\prime}\right)}\right] \\
& =\max _{0 \leqslant \tau^{\prime} \leqslant \tau}\left[\sqrt{\left(\frac{\left\langle\delta_{\mathrm{n}}\left(\tau^{\prime}\right)\right\rangle}{\delta_{\text {on }}}\right)^{2}+\left(\frac{\left\langle\delta_{\mathrm{t}}\left(\tau^{\prime}\right)\right\rangle}{\delta_{\text {ot }}}\right)^{2}}\right]
\end{aligned}
$$


Then the single-mode constitutive relationship (Equation 2) can be modified as follows for mixed-mode delamination

8. $t_{\alpha}=\phi_{\mathrm{m}} K_{\alpha} \delta_{\alpha}=\left(1-d_{\mathrm{m}}\right) K_{\alpha} \delta_{\alpha}$

So far, the constitutive relationship has been developed for the interfacial behaviour before cracking, a damage law is also needed to identify when the interfacial cracking occurs. In Alfano and Crisfield (2001), an energy-based damage formulation is presented

9. $\left(\frac{G_{\mathrm{n}}}{G_{\mathrm{cn}}}\right)+\left(\frac{G_{\mathrm{t}}}{G_{\mathrm{ct}}}\right)=1$

where $G_{\mathrm{n}}$ and $G_{\mathrm{t}}$ are fracture energies calculated by the following equations

10. $G_{\mathrm{n}}=\int t_{\mathrm{n}} \mathrm{d} \delta_{\mathrm{n}}, \quad G_{\mathrm{t}}=\int t_{\mathrm{t}} \mathrm{d} \delta_{\mathrm{t}}$

Meanwhile $G_{\text {cn }}$ and $G_{\text {ct }}$ are critical fracture energies calculated in accordance with the single-mode delamination. For the bilinear traction/relative displacement relationship, the value of critical energy could be obtained by calculating the area under the bilinear curve

11. $G_{\mathrm{cn}}=\frac{1}{2} T_{\mathrm{cn}} \delta_{\mathrm{cn}}, \quad G_{\mathrm{ct}}=\frac{1}{2} T_{\mathrm{ct}} \delta_{\mathrm{ct}}$

where the maximum traction along the normal and tangential directions $\left(T_{\mathrm{cn}}, T_{\mathrm{ct}}\right)$ can be set equal to normal and tangential bond strength $\left(f_{\mathrm{nb}}, f_{\mathrm{tb}}\right)$ respectively, provided in Table 2 .

\subsection{Finite-element model}

Input data for CZM and the contact pair (Conta173 and Target 171 in Ansys) are listed in Table 2. Because cementitious coating material behaves like a weak concrete, the Solid65 element with the William-Warnke model (William, 1974), which has been specially developed for simulating concrete cracking and crush- ing, is employed to address the internal damage in the cementitious coating. In this work, the ambient hydrostatic stress for the William-Warnke model is assumed to be low. Thus, default values are used for stresses under ambient hydrostatic stress state. A crack in the Solid65 element is represented through modification of the stress-strain relations by introducing a plane of weakness in a direction normal to the crack face. Hence the shear transfer coefficients $\left(\beta_{\mathrm{t}}\right.$ and $\left.\beta_{\mathrm{c}}\right)$ for the open and closed cracks should be specified. The input data for the Solid65 elements are also listed in Table 2.

Non-linear compressive behaviour of the cementitious material is addressed by introducing a multi-linear kinematic hardening (MKIN) material model to the Solid65 element. The input data are shown in Table 3 in accordance with the results from compressive strength tests (Jiang, 2012).

Element Solid45 with a bilinear kinematic hardening (BKIN) material model is employed to simulate the steel plate. For the BKIN model, a yield stress $f_{\mathrm{y}}$ and tangent modulus $E_{\mathrm{p}}$ are required to describe the post-yield behaviour. Input data for steel material properties are also shown in Table 2.

The finite-element model for simulating the CW1-1 specimen test is shown in Figure 1(e). The dimensions of steel plate and coating are $800 \mathrm{~mm} \times 100 \mathrm{~mm} \times 20 \mathrm{~mm}$ and $500 \mathrm{~mm} \times 60 \mathrm{~mm} \times$ $20 \mathrm{~mm}$ respectively. This model will be used to simulate both the tension and compression sides.

\subsection{Comparison and validation of CZFE scheme}

The proposed CZFE scheme has been previously employed by the authors for investigating interfacial stress distribution between the coating and steel substrate on axially loaded steel members, and verified by comparing against an analytical interlaminar stress solution, directly constrained nodal displacements and

\begin{tabular}{lcccccc}
\hline Data no. & 1 & \multicolumn{1}{c}{2} & \multicolumn{1}{c}{3} & 4 & 5 & 6 \\
\hline Strain & 0 & 0.005 & 0.010 & 0.02 & 0.03 & 0.04 \\
Stress: MPa & 0 & 0.20165 & 0.4033 & 0.53 & 0.58 & 0.59
\end{tabular}

Table 3. MKIN material model for cementitious coating

$\underline{ }$

\begin{tabular}{|c|c|c|c|c|}
\hline $\begin{array}{l}\text { CZM and contact } \\
\text { elements }\end{array}$ & $\begin{array}{c}K_{\mathrm{n}} \\
16 \mathrm{~N} / \mathrm{mm}^{3}\end{array}$ & $\begin{array}{c}\delta_{\mathrm{cn}} \\
0.005\end{array}$ & $\begin{array}{c}K_{\mathrm{t}} \\
10 \mathrm{~N} / \mathrm{mm}^{3}\end{array}$ & $\begin{array}{c}\delta_{\mathrm{ct}} \\
0.014\end{array}$ \\
\hline Cementitious coating & $\begin{array}{c}E_{\mathrm{c}} \\
40 \cdot 33 \mathrm{MPa}\end{array}$ & $\begin{array}{c}v \\
0 \cdot 2\end{array}$ & $\begin{array}{c}f_{\mathrm{t}} \\
0.05 \mathrm{MPa}\end{array}$ & $\begin{array}{c}f_{\mathrm{c}} \\
0.59 \mathrm{MPa}\end{array}$ \\
\hline Steel & $\begin{array}{c}E \\
200 \mathrm{GPa}\end{array}$ & $\begin{array}{c}v \\
0 \cdot 3\end{array}$ & $\begin{array}{c}E_{\mathrm{p}} \\
1000 \mathrm{MPa}\end{array}$ & $\begin{array}{c}f_{\mathrm{y}} \\
315 \mathrm{MPa}\end{array}$ \\
\hline
\end{tabular}

Table 2. Material properties 
contact analysis using zero-length spring elements (shown in Figure 4 as 'Analytical solution', 'Displacement constrained' and 'Combin 39' respectively). In Figure 4, all the data points are obtained along the centroidal axis of the interface, with only half the length $(0 \sim 50 \mathrm{~mm})$ depicted, owing to the symmetry of the interface.

The analytical interlaminar stress solution, initially proposed by Wang (2008) in his doctoral dissertation, is based on elastic fracture mechanics with an assumption that the tangential and normal interlaminar stresses could be expressed as follows

12.

$$
\tau_{0}=\sum_{n=1}^{\infty} a_{n} \sin \frac{n \pi x}{l}, \sigma_{0}=\sum_{n=1}^{\infty} b_{n} \cos \frac{n \pi x}{l}
$$

where the parameters $a_{n}$ and $b_{n}$ are determined by applying mechanical equilibriums and the minimum energy principle.

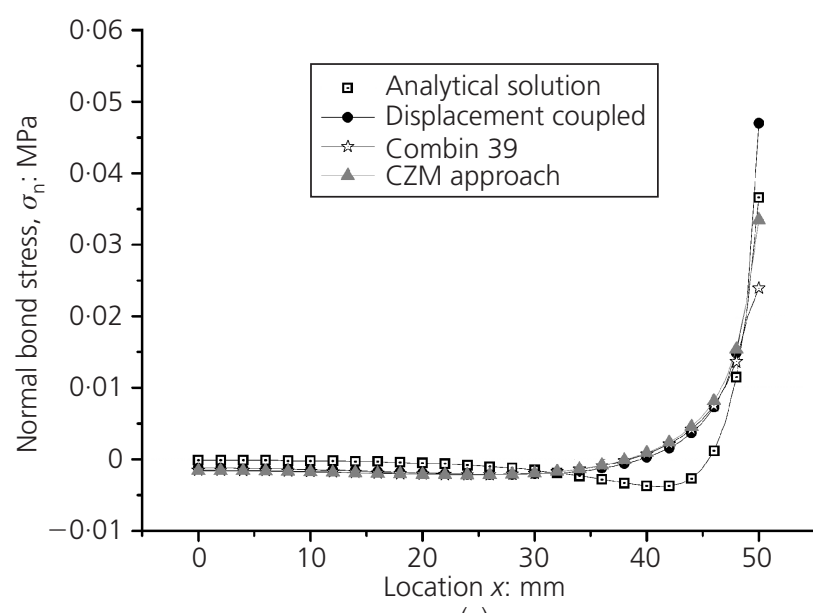

(a)

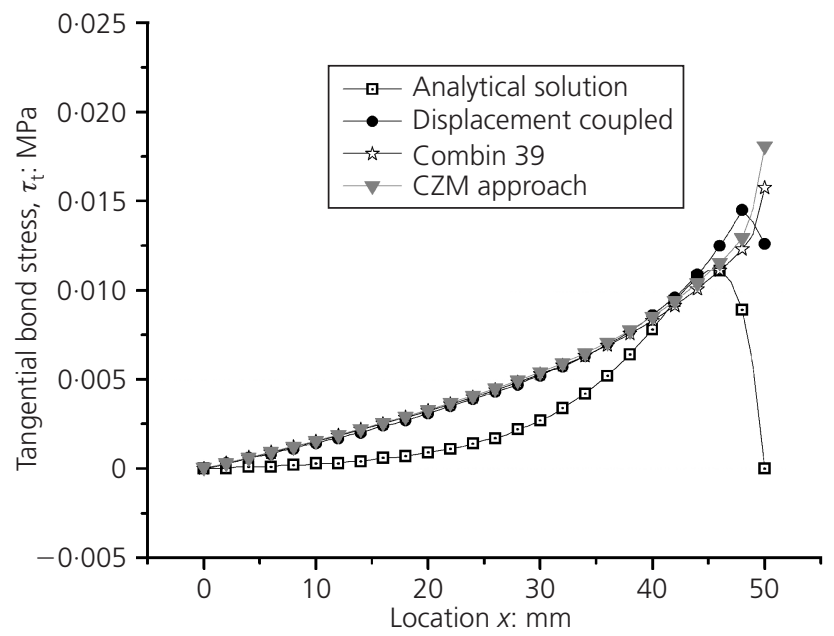

(b)

Figure 4. Comparison of interfacial (bond) stresses for axially loaded case: (a) normal direction; (b) tangential direction
Wang (2008) proposed his analytical solution for the interfacial stresses as below.

13.

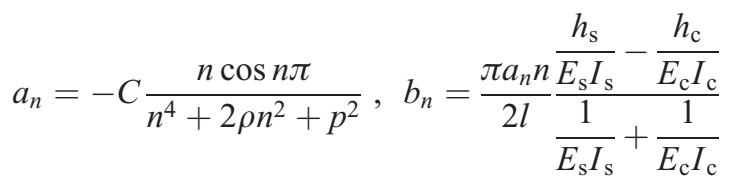

$$
C=\frac{\frac{2}{\pi}\left[\frac{h_{\mathrm{c}} N}{b h_{\mathrm{s}} E_{\mathrm{s}} l}+\frac{1}{\pi E_{\mathrm{s}}}\left(1+\frac{2 h_{\mathrm{c}}}{h_{\mathrm{s}}}\right) \sum_{n=1}^{\infty} \frac{a_{n}}{n} \cos n \pi\right]}{\frac{\pi^{2} h_{\mathrm{c}}^{2}}{4 l^{4}}\left[\frac{1}{5 E_{\mathrm{c}}}+\frac{1}{E_{\mathrm{s}}} \frac{h_{\mathrm{s}}}{h_{\mathrm{c}}}\left(\frac{1}{2}+\frac{h_{\mathrm{s}}}{3 h_{\mathrm{c}}}+\frac{h_{\mathrm{s}}^{2}}{15 h_{\mathrm{c}}^{2}}\right)\right]}
$$

15.

$$
p^{2}=\frac{\frac{1}{\pi^{2}}\left(\frac{1}{E_{\mathrm{c}}}+\frac{1}{E_{\mathrm{s}}} \frac{2 h_{\mathrm{c}}}{h_{\mathrm{s}}}\right)}{\frac{\pi^{2} h_{\mathrm{c}}^{2}}{4 l^{4}}\left[\frac{1}{5 E_{\mathrm{c}}}+\frac{1}{E_{\mathrm{s}}} \frac{h_{\mathrm{s}}}{h_{\mathrm{c}}}\left(\frac{1}{2}+\frac{h_{\mathrm{s}}}{3 h_{\mathrm{c}}}+\frac{h_{\mathrm{s}}^{2}}{15 h_{\mathrm{c}}^{2}}\right)\right]}
$$

16.

$$
\rho=\frac{\frac{1}{3}\left(\frac{1}{G_{\mathrm{c}}}-\frac{2 \mu_{\mathrm{c}}}{E_{\mathrm{c}}}\right)+\frac{h_{\mathrm{s}}}{6 h_{\mathrm{c}}}\left(\frac{1}{G_{\mathrm{s}}}-\frac{2 \mu_{\mathrm{s}}}{E_{\mathrm{s}}}\right)+\left(\frac{\mu_{\mathrm{c}}}{E_{\mathrm{c}}}-\frac{\mu_{\mathrm{s}}}{E_{\mathrm{s}}}\right)}{\frac{\pi^{2} h_{\mathrm{c}}^{2}}{2 l^{4}}\left[\frac{1}{5 E_{\mathrm{c}}}+\frac{1}{E_{\mathrm{s}}} \frac{h_{\mathrm{s}}}{h_{\mathrm{c}}}\left(\frac{1}{2}+\frac{h_{\mathrm{s}}}{3 h_{\mathrm{c}}}+\frac{h_{\mathrm{s}}^{2}}{15 h_{\mathrm{c}}^{2}}\right)\right]}
$$

In the simulation employing zero-length spring, at each pair of matching nodes, three spring elements of Combin 39 are employed to simulate the contact in normal, longitudinal tangential and transverse tangential directions respectively. The constitutive relationships of Combin 39 elements along normal and tangential directions are set in accordance with the material properties obtained from tests by Jin (2011) and Chen et al. (2012b).

From Figure 4(a), normal interfacial (bond) stress curves are generally of the same shape with maximum normal interfacial stress located at the very end of the interface; however, differences can be seen near the end $(40 \sim 50 \mathrm{~mm})$ of the interface. It is noticed that there is a $10 \mathrm{~mm}(35 \sim 45 \mathrm{~mm})$ compressive (negative) zone for the analytical solution, but all the numerical approaches did not capture this phenomenon, which is due to the chosen discretisation and can be improved with a finer mesh. However, since negative normal bond stress will not cause debonding and affect the damage mode, it was considered acceptable to retain the chosen mesh.

For the tangential interfacial stress, results from different solutions also have similar shapes, except for the difference at the 
end of the interface, as plotted in Figure 4(b). For the analytical solution, the interfacial stress drops to zero at the end. However, boundary conditions could not be precisely satisfied in finiteelement analyses given the continuity limitation of displacement shape functions and the presence of a singularity at the corner of the coating-steel interface. A finer mesh may help but cannot fundamentally solve this problem.

\section{Simulation results}

The coatings on the tension side and the compression side show different damage mechanisms (Figure 5), which will be described in detail in the following subsections.

\subsection{Tension side}

When the steel plate is in pure bending, the curvature at the neutral plane is adopted to interpret the damage, since strain can be represented using curvature and depth. The damage propagation has been detailed in Table 4 and the simulated damage mechanism is shown in Figure 5(a). The contact element status, contour plot of normal bond stress and the first principal stress in the coating are shown in Figures 6, 7 and 8 respectively. From Table 4 and Figures 6-8, the damage mechanisms can be clearly identified. When the curvature at the neutral plane reaches $0.37 \times 10^{-4} \mathrm{~mm}^{-1}$, there is no damage. But when the curvature reaches $0.39 \times 10^{-4} \mathrm{~mm}^{-1}$, cracks initiate at both ends of the interface (Figure 6(b) and Figure 7(b)), followed by the first pair of transverse cracks and surface cracks (Figure 7(c) and Figure $8(\mathrm{c}))$ at the curvature of $0.42 \times 10^{-4} \mathrm{~mm}^{-1}$. The second pair of transverse cracks occurs at the curvature of $0.45 \times 10^{-4} \mathrm{~mm}^{-1}$ (Figure 7(d) and Figure 8(d)). With further increase of curvature, the interfacial cracks propagate towards the centre, more transverse cracks occur (Figure 7(e) and Figure 8(e)) and centre cracks
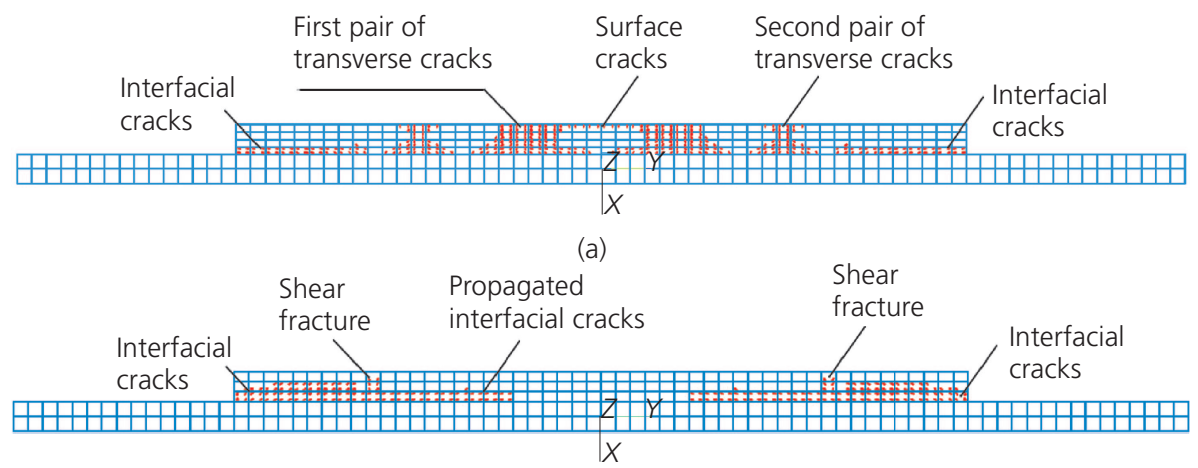

(b)

Figure 5. Damage mechanism of cementitious coating on steel member in bending: (a) tension side; (b) compression side

\begin{tabular}{ll}
\hline Neutral curvature: $\mathrm{mm}^{-1}$ & Damage propagation on tension side \\
\hline $0.37 \times 10^{-4}$ & $\begin{array}{l}\text { No damage, critical condition for interfacial crack } \\
\text { Interfacial cracks initiate at both ends }\end{array}$ \\
$0.39 \times 10^{-4}$ & First pair of transverse cracks in the centre part and some surface cracks \\
$0.42 \times 10^{-4}$ & Second pair of transverse cracks \\
$0.45 \times 10^{-4}$ & Interfacial crack developed with increased length \\
$0.58 \times 10^{-4}$ & More transverse cracks \\
$1.26 \times 10^{-4}$ & Damage propagation on compression side \\
\hline Neutral curvature: $\mathrm{mm}^{-1}$ & No damage yet, critical condition for interfacial damage \\
\hline $1.056 \times 10^{-4}$ & Damage initiates at ends of interface \\
$1.063 \times 10^{-4}$ & Delamination at both ends of interface \\
$1.064 \times 10^{-4}$ & Interfacial crack propagates towards centre \\
$1.068 \times 10^{-4}$ & Bending fracture at both ends \\
$1.069 \times 10^{-4}$ & More severe interfacial damage and peel off of coatings \\
$1.112 \times 10^{-4}$ & curvature at \\
Table 4. Damage propagation related with steel \\
neutral plane
\end{tabular}




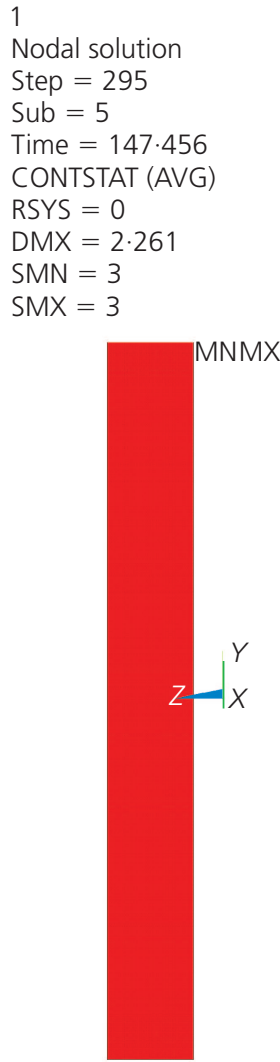

(a)

Nodal solution
Step $=317$
Sub $=5$
Time $=158 \cdot 456$
CONTSTAT (AVG)
RSYS $=0$
DMX $=2 \cdot 429$
SMN $=1$
SMX $=3$

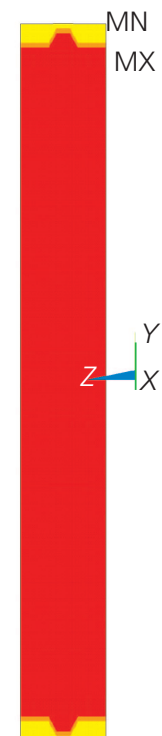

(b)

1
Nodal solution
Step $=331$
Sub $=5$
Time $=165 \cdot 456$
CONTSTAT (AVG)
RSYS $=0$
DMX $=2 \cdot 536$
SMN $=1$
SMX $=3$

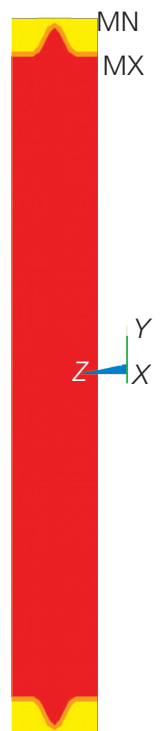

(c)
Nodal solution

Step $=332$

Sub $=5$

Time $=165 \cdot 956$

CONTSTAT (AVG)

RSYS $=0$

$\mathrm{DMX}=2 \cdot 544$

$\mathrm{SMN}=1$

$\mathrm{SMX}=3$

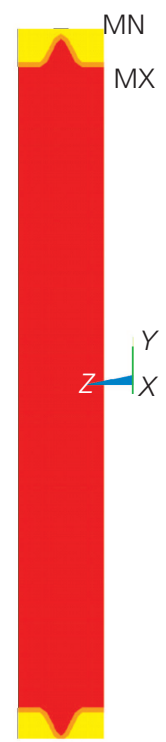

(d)

Step $=462$
Sub $=6$
Time $=231$
CONTSTAT (AVG)g)
RSYS $=0$
DMX $=3 \cdot 541$
SMN $=2$
SMX $=3$

Nodal solution

Step $=1000$

$\mathrm{Sub}=6$

Time $=500$

CONTSTAT (AVG)

RSYS $=0$

$\mathrm{DMX}=7.664$

$\mathrm{SMN}=1$

$\mathrm{SMX}=3$

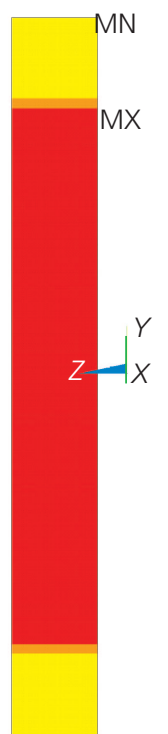

(e)

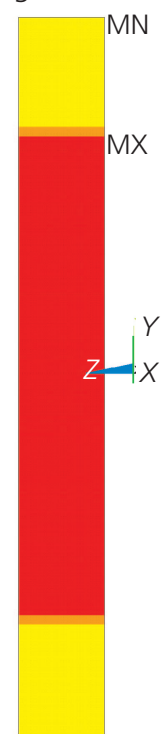

(f)

Near contact

Sliding

Sticking

Figure 6. Contact element status at different steel curvature on tension side $\left(\phi_{\mathrm{s}}: \mathrm{mm}^{-1}\right)$ : (a) $0.37 \times 10^{-4}$; (b) $0.39 \times 10^{-4}$;

(c) $0.42 \times 10^{-4}$; (d) $0.45 \times 10^{-4}$; (e) $0.58 \times 10^{-4}$;

(f) $1.26 \times 10^{-4}$

at the top surface occur at the late period (Figure 7(f) and Figure $8(\mathrm{f})$ ). The final failure mode is that the coating fractures into several segments with delamination at both ends. Compared to the damage mechanisms observed in cementitious coatings on axially loaded steel members in tension, the coating on the tension side in bending undergoes more severe interfacial damage with longer and larger delamination, as well as the occurrence of surface cracks.

The damage mechanism and damage propagation from the simulation agrees well with the test results as shown in Figure 2(a), although differences exist in the correlation of curvatures to different damage states.

Interfacial cracking can also be detected from Figure 9(a) and Figure 9(b). When the curvature increases from $0.37 \times$ $10^{-4} \mathrm{~mm}^{-1}$ to $0.39 \times 10^{-4} \mathrm{~mm}^{-1}$, both the normal bond stress and tangential bond stress at the ends drop from maximum values to zero, which indicates the occurrence of delamination. The occurrence of transverse cracks can be detected from Figure 9(c), Figure 9(d) and Figure 10, as the first principal stress at the location of the crack drops from its maximum value to zero once the crack occurs. The difference between the centre parts of Figure $9(\mathrm{c})$ and Figure $9(\mathrm{~d})$ for curvatures of $0.415 \times 10^{-4} \mathrm{~mm}^{-1}$ and $0.448 \times 10^{-4} \mathrm{~mm}^{-1}$ denotes the occurrence of non-throughthickness transverse cracks starting from the top surface, as the first principal stress at the top surface drops from its maximum value to zero, but no drop is observed for the first principal stress at the surface $5 \mathrm{~mm}$ below (shown in Figures 7(f) and 8(f)). This non-through-thickness crack is caused by the effect of curvature.

\subsection{Compression side}

The same finite-element model has been adopted to simulate damage propagation in the cementitious coating on the compression side. Figure 5(b) shows the simulated damage mechanism, which is explained in Table 4 and Figures 11-13. When the curvature at the neutral plane reaches $1.056 \times 10^{-4} \mathrm{~mm}^{-1}$, there is no damage. When the curvature reaches $1.063 \times 10^{-4} \mathrm{~mm}^{-1}$, damage initiates at both ends of interface (Figure 11(a)), and then interfacial cracks occur at both ends (Figure 12(a) and Figure 12(c)). With a further increase of curvature, the interfacial cracks propagate towards the centre (Figures 11(c) and 11(d), 


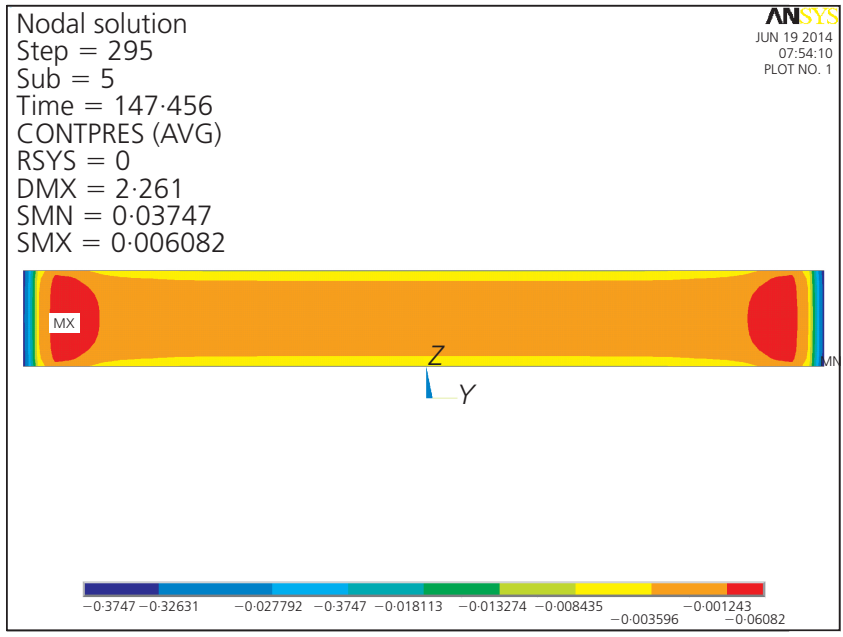

(a)

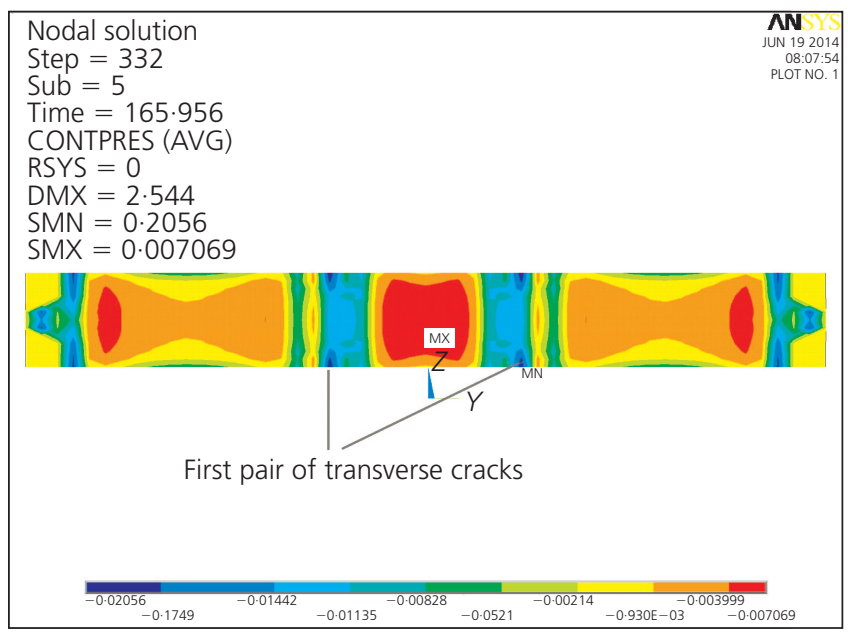

(c)

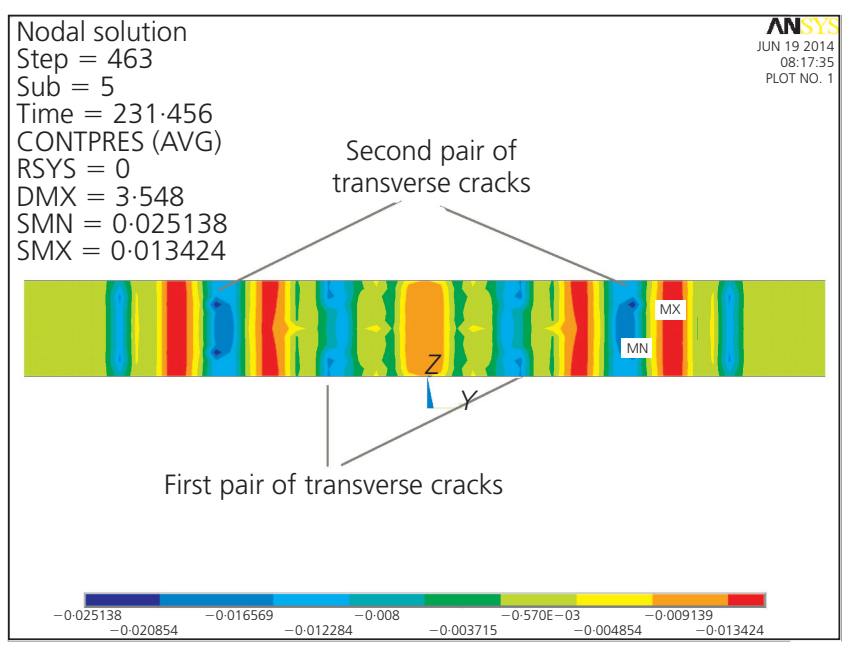

(e)

Figure 7. Contour plot of normal bond stress at different steel curvature on tension side $\left(\phi_{\mathrm{s}}: \mathrm{mm}^{-1}\right)$ : (a) $0.37 \times 10^{-4}$;

(b) $0.39 \times 10^{-4}$; (c) $0.42 \times 10^{-4}$; (d) $0.45 \times 10^{-4}$;

(e) $0.58 \times 10^{-4}$; (f) $1.26 \times 10^{-4}$

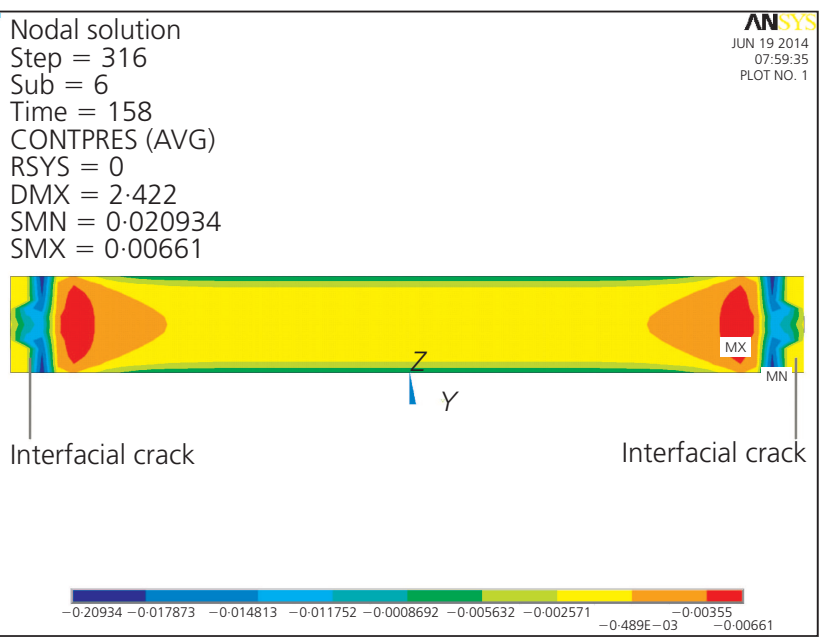

(b)

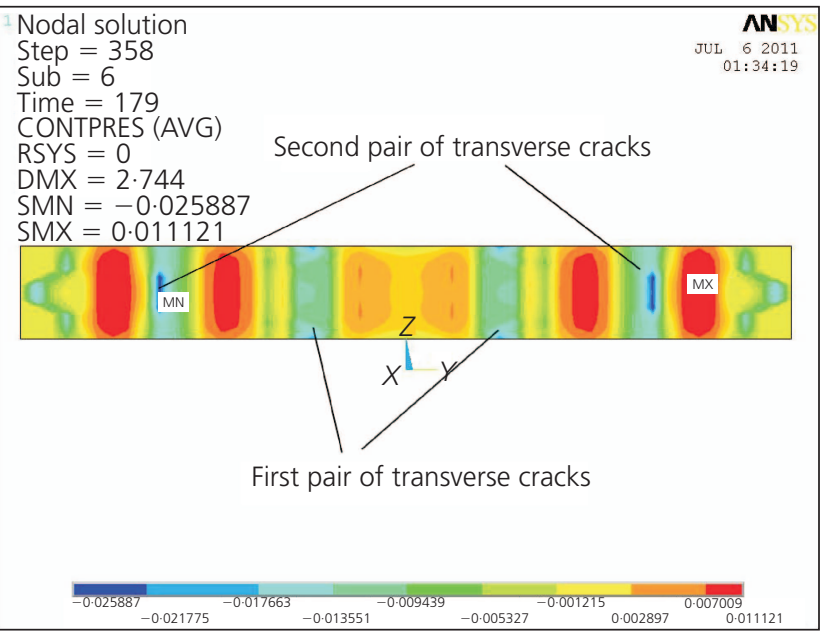

(d)

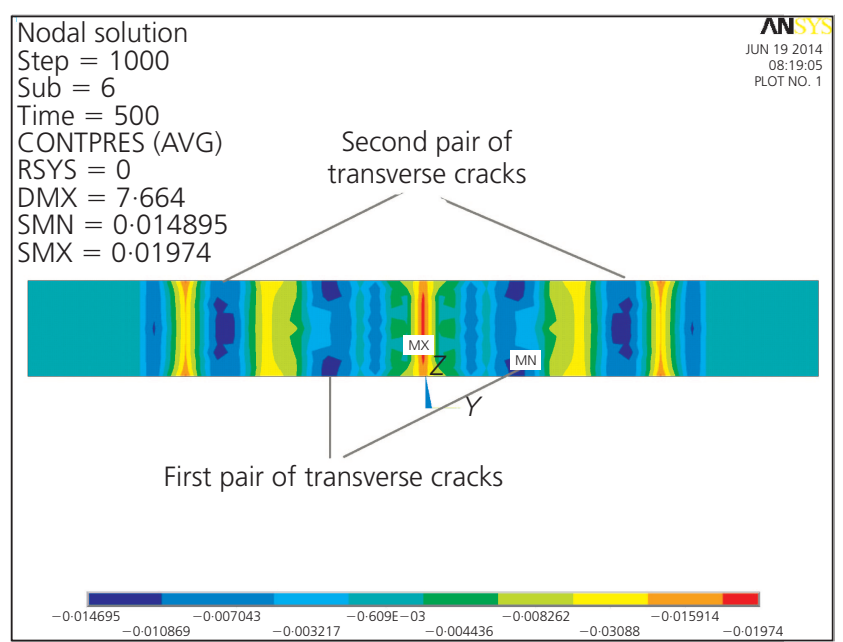

(f) 


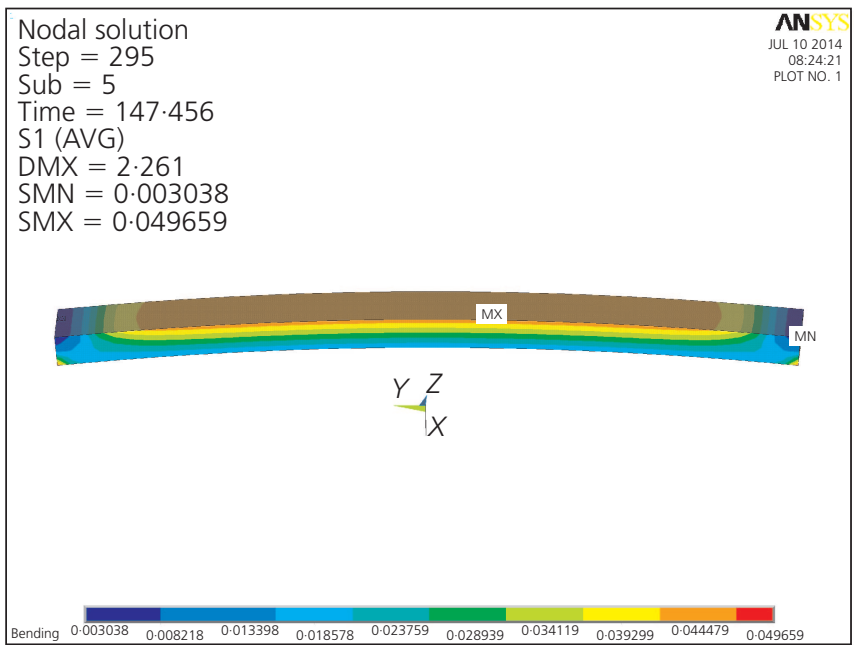

(a)

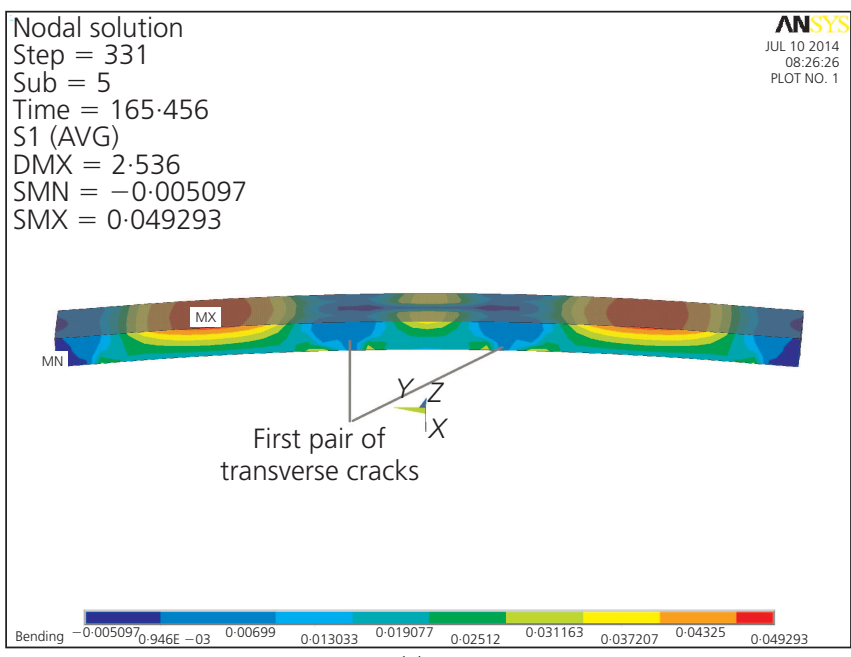

(c)

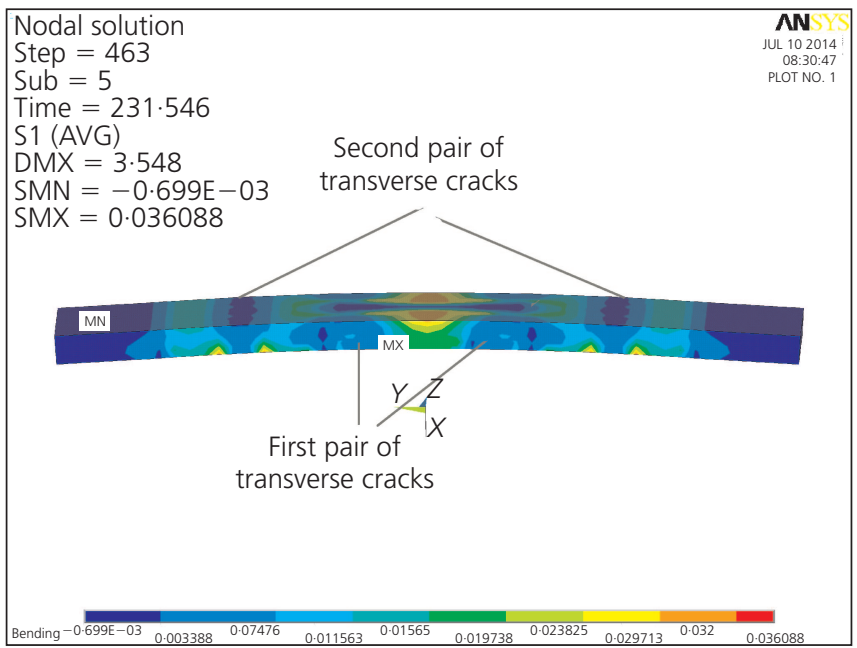

(e)

Figure 8. Contour plot of first principal stress in coating at different steel curvature on tension side $\left(\phi_{\mathrm{s}}: \mathrm{mm}^{-1}\right)$ :

(a) $0.37 \times 10^{-4}$; (b) $0.39 \times 10^{-4}$; (c) $0.42 \times 10^{-4}$;

(d) $0.45 \times 10^{-4}$; (e) $0.58 \times 10^{-4}$; (f) $1.26 \times 10^{-4}$

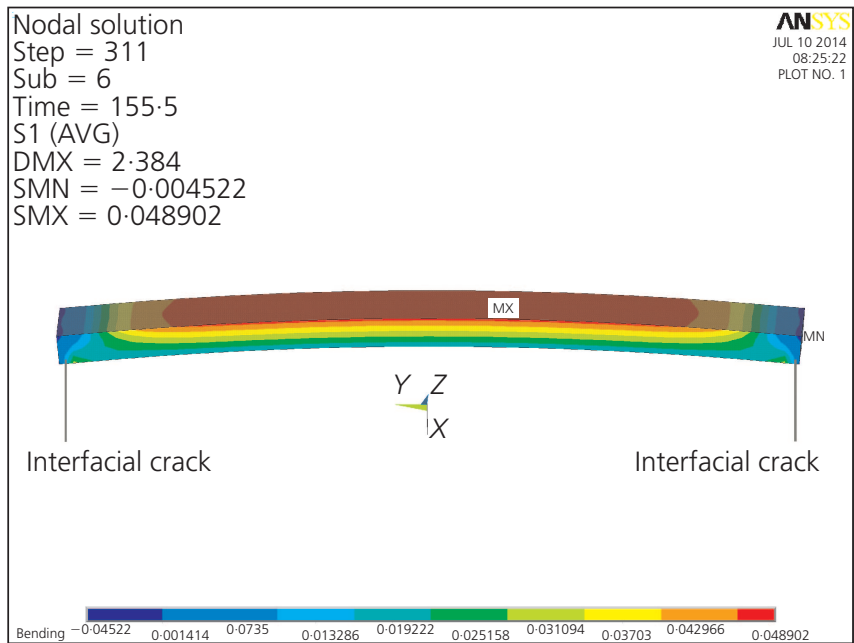

(b)

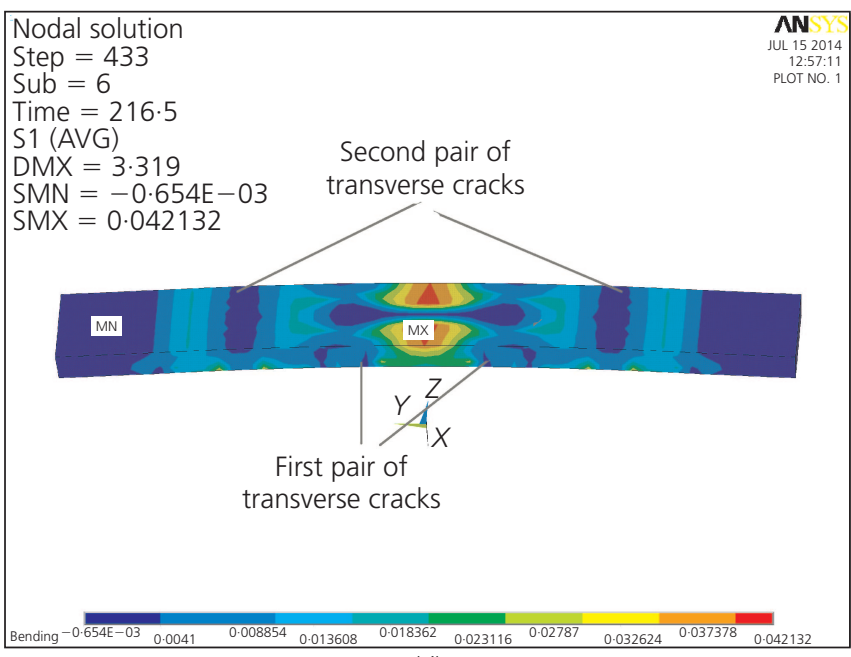

(d)

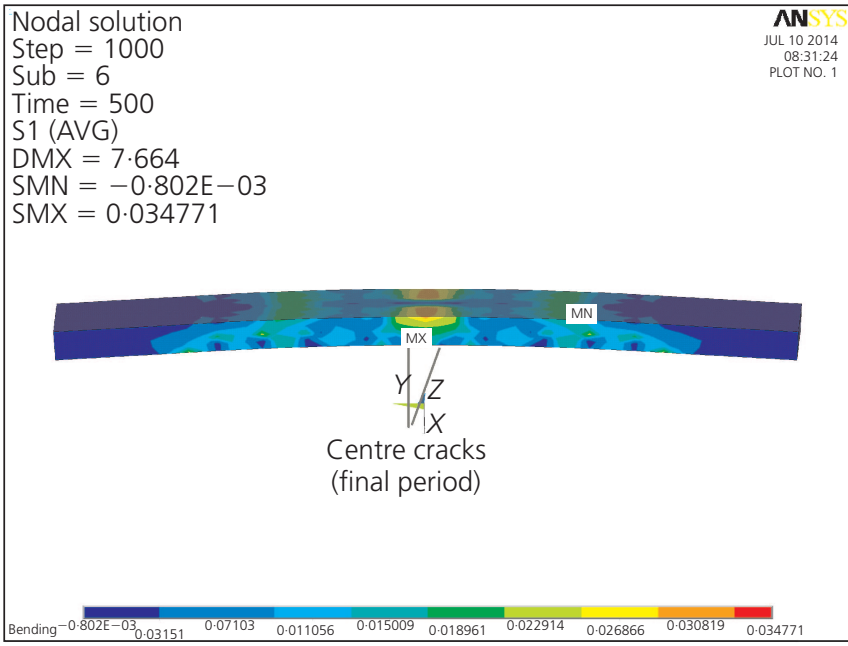

(f) 


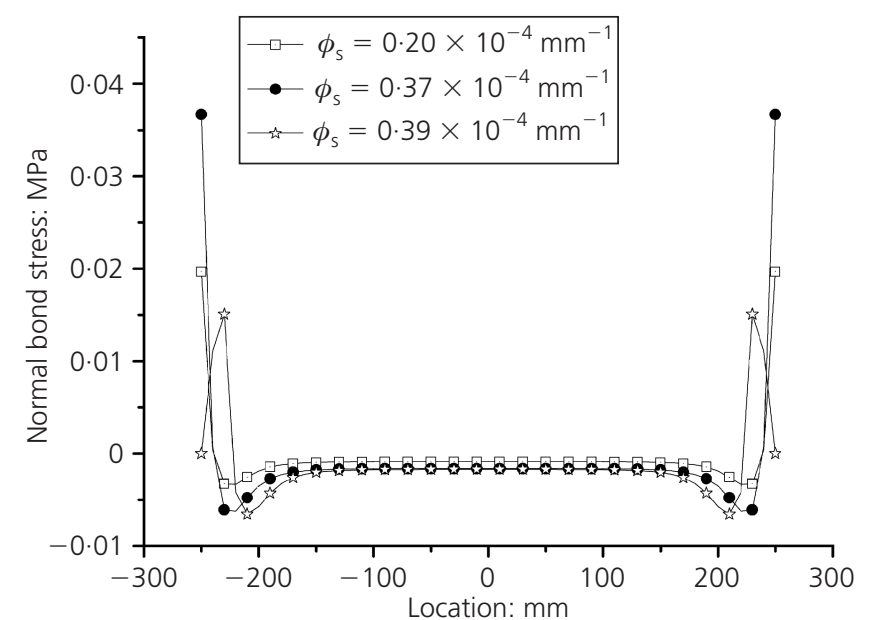

(a)

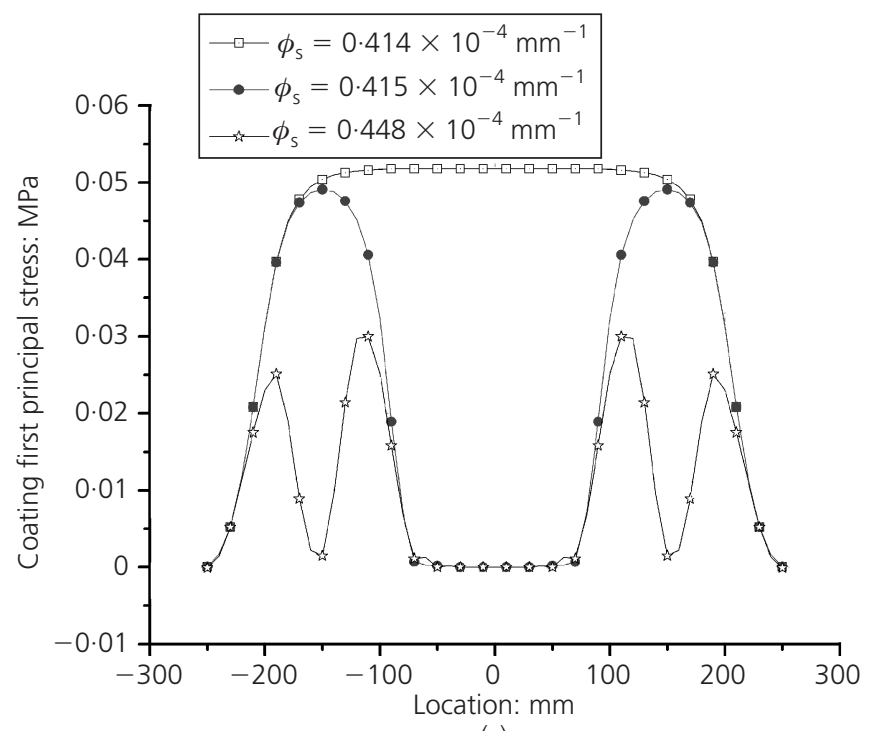

(c)

Figure 9. Stress distribution along the axis at different steel curvature on tension side: (a) normal direction; (b) tangential direction; (c) first principal stress of coating at top surface;

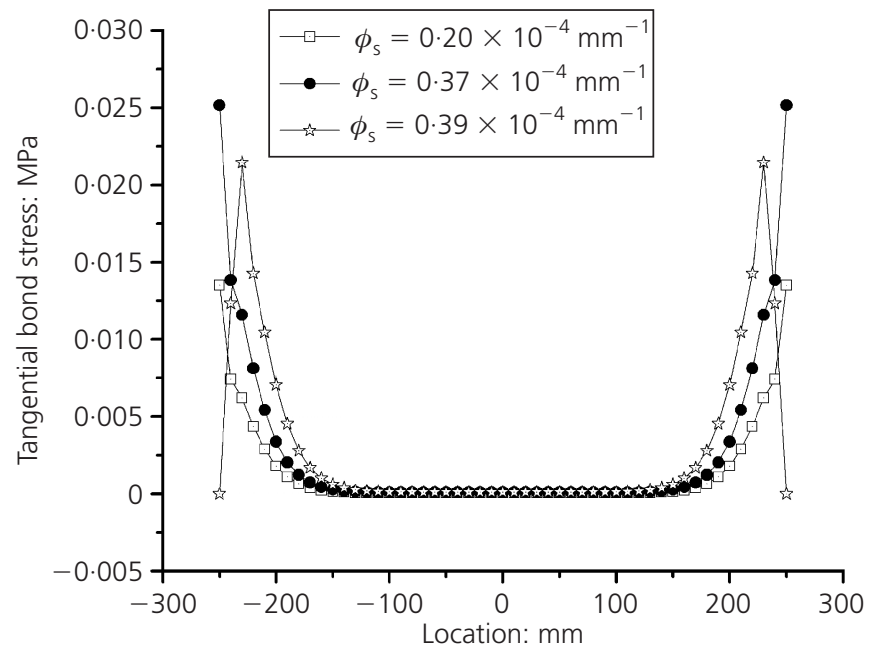

(b)

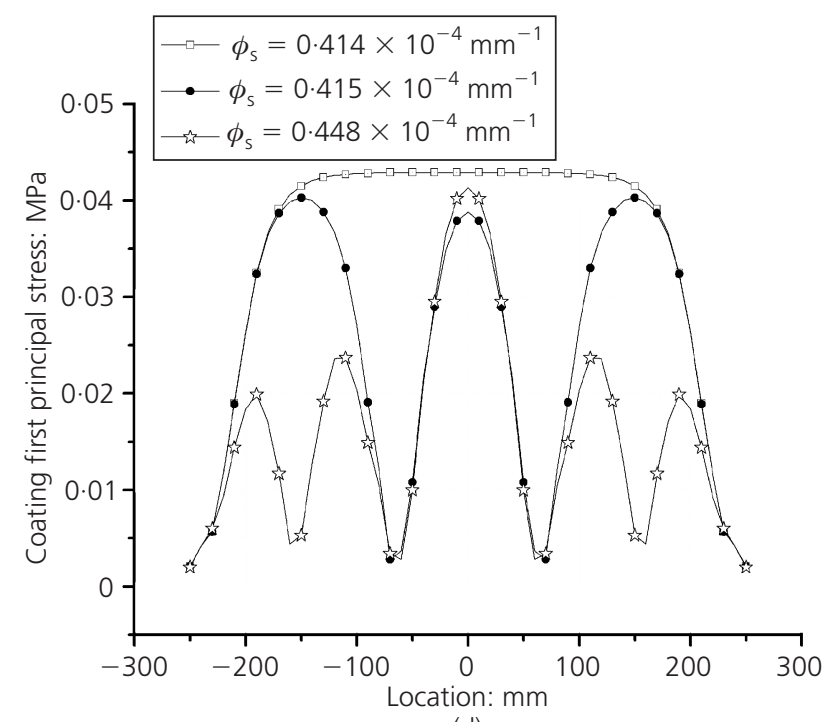

(d)

(d) first principal stress of coating at the surface $15 \mathrm{~mm}$ above the interface
Figure 12(b) and Figure 12(d)) and shear fractures occur when the curvature reaches $1.064 \times 10^{-4} \mathrm{~mm}^{-1}$ (Figure 12(e)). The shear fracture is caused by the moment from the uplifting force at the end due to the effect of curvature. The damage mechanism and damage propagation observed from simulation agrees well with the test results, as shown in Figure 2(b), although the correlation of curvature with different damage states is not exactly the same. The effect of curvature in bending makes this behaviour somewhat different from the damage mechanisms observed in cementitious coatings on axially loaded steel members in compression, where only delamination damage is observed.

Initiation of interfacial cracks can be seen in Figure 13. When the curvature increases from $1.057 \times 10^{-4} \mathrm{~mm}^{-1}$ to $1.064 \times$
$10^{-4} \mathrm{~mm}^{-1}$, a sharp change can be observed in the distributions of both the normal and tangential bond stresses, where the maximum values at both ends drop to zero, indicating failure of the bond.

\section{Parametric study on coating size}

Further tests are carried out to investigate the influence of coating size, thickness and length on the damage mechanisms. A number of numerical examples, of coating sizes $500 \times 60 \times 30$, $500 \times 60 \times 40, \quad 300 \times 60 \times 20$ and $700 \times 60 \times 20$, are simulated and compared against the reference case of $500 \times 60 \times 20$ $\left(L \times W \times T, \mathrm{~mm}^{3}\right)$. The dimensions of corresponding steel plates are, $\quad 800 \times 100 \times 20, \quad 800 \times 100 \times 20, \quad 600 \times 60 \times 20$ and $900 \times 60 \times 20$.

Damage propagations against curvature at the neutral plane for 


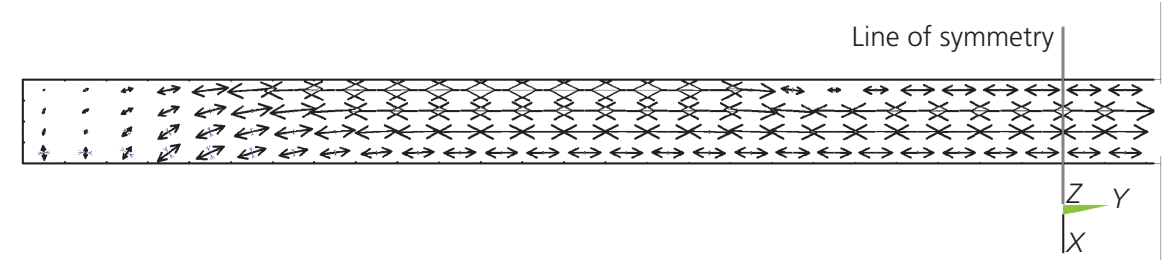

(a)

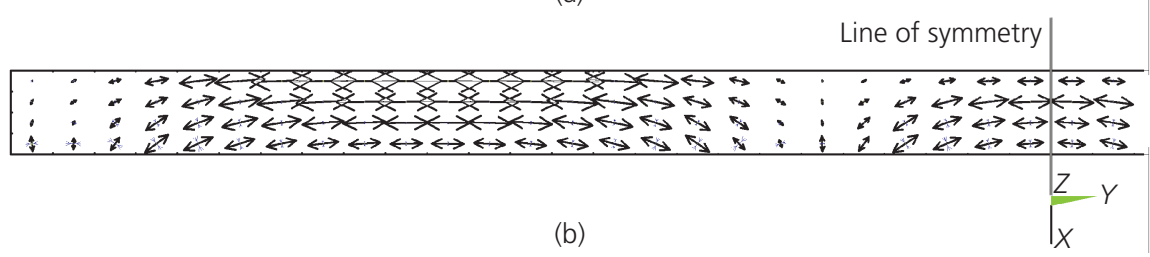

Line of symmetry

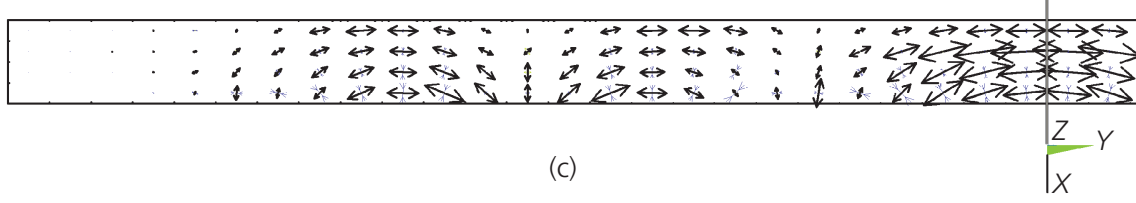

Figure 10. Propagation of first principal stress vector plot of half coating considering symmetry on tension side $\left(\phi_{\mathrm{s}}: \mathrm{mm}^{-1}\right)$ :

(a) $0.414 \times 10^{-4}$; (b) $0.415 \times 10^{-4}$; (c) $0.448 \times 10^{-4}$

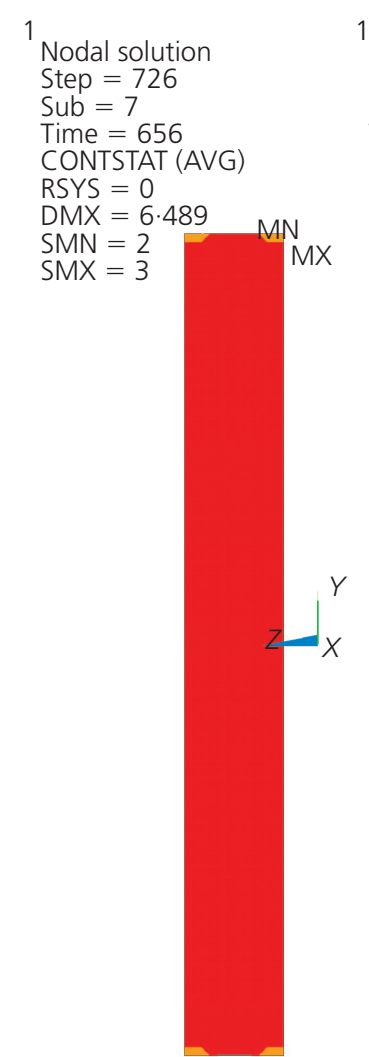

(a)

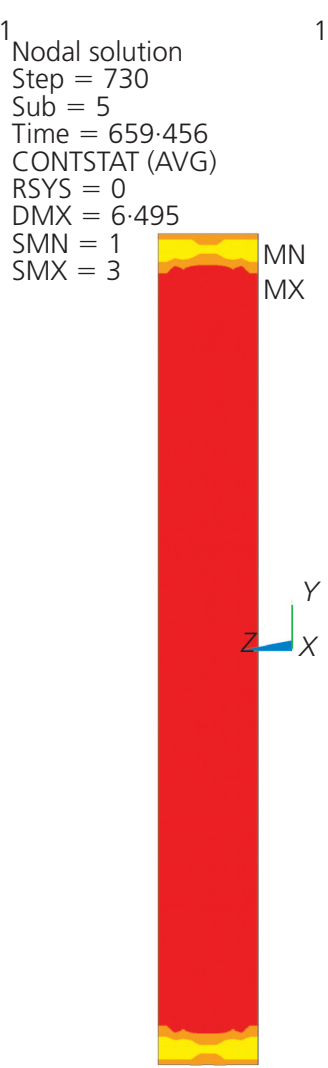

(b)

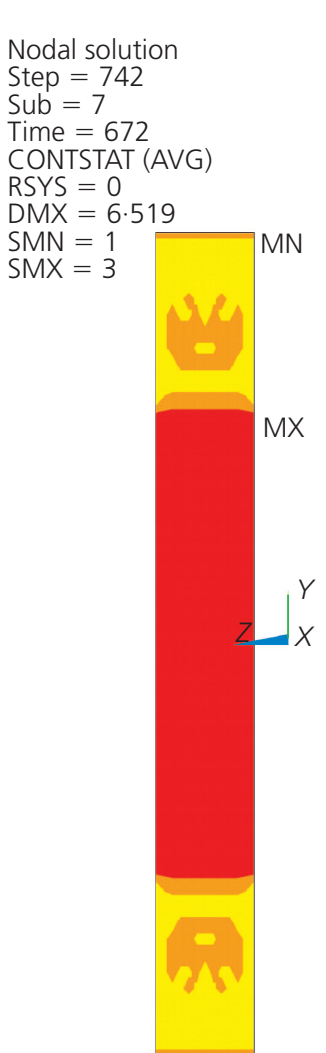

(c)
1

Nodal solution

Step $=745$

$\mathrm{Sub}=5$

Time $=674.456$

CONTSTAT (AVG)

RSYS $=0$

DMX $=6.524$

$\mathrm{SMN}=1=\mathrm{MN}$

$\mathrm{SMX}=3$

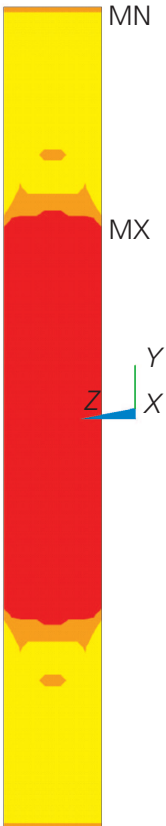

(d) Nodal solution Step $=878$

Sub $=5$

Time $=807 \cdot 456$

CONTSTAT (AVG)

$\mathrm{RSYS}=0$

$\mathrm{DMX}=6.78$

$\mathrm{SMN}=1$

$S M X=3$

Near contact

Sliding

Sticking

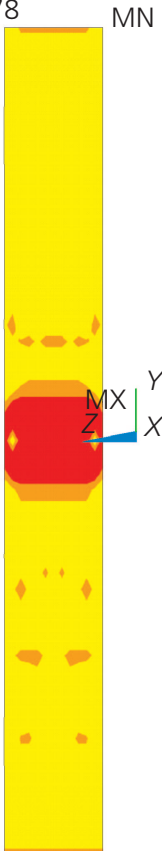

(e)

Figure 11. Contact element status at different steel curvature on compression side $\left(\phi_{\mathrm{s}}: \mathrm{mm}^{-1}\right)$ : (a) $1.063 \times 10^{-4}$; (b) $1.064 \times 10^{-4}$; (c) $1.068 \times 10^{-4}$; (d) $1.069 \times 10^{-4}$; (e) $1.112 \times 10^{-4}$ 


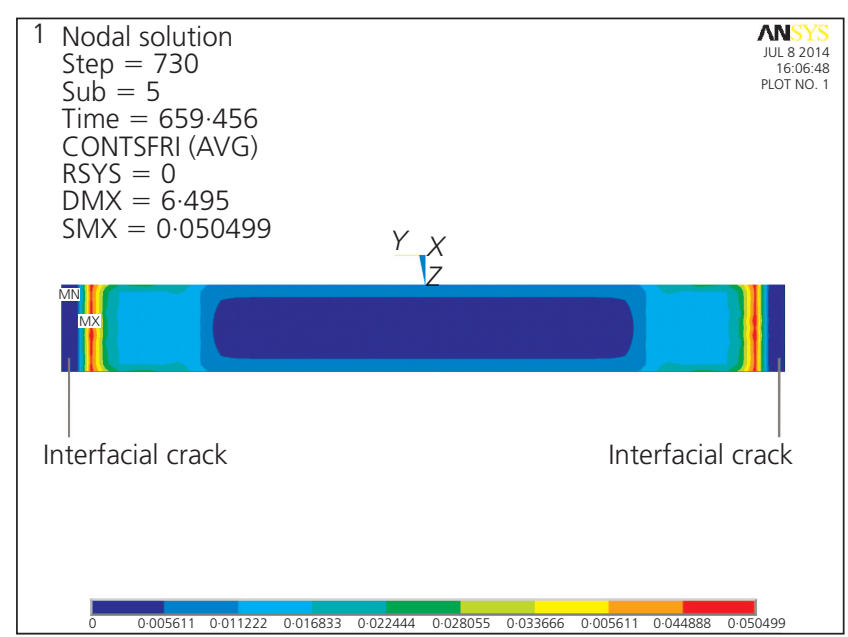

(a)

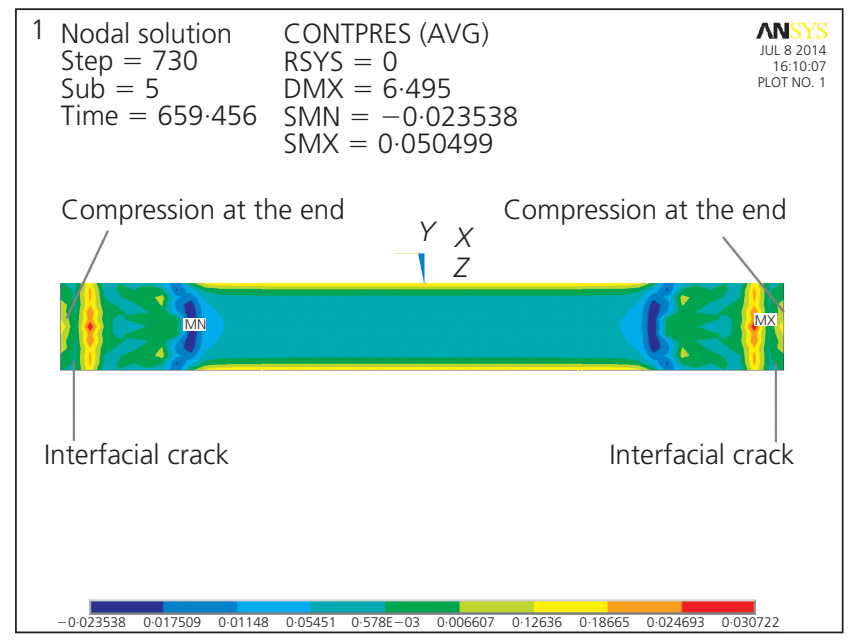

(c)

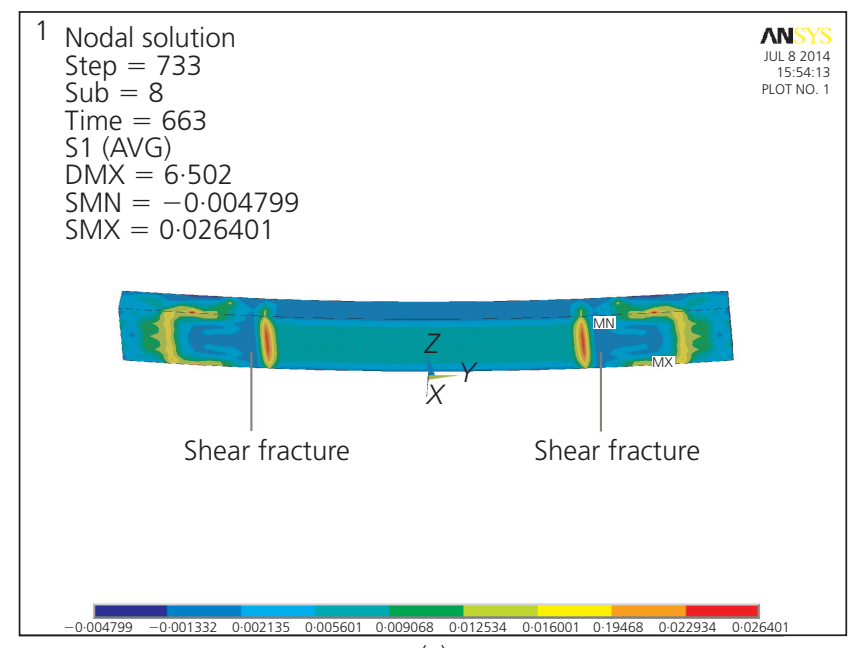

(e)

Figure 12. Contour plot of stress at different steel curvature on compression side $\left(\phi_{\mathrm{s}}: \mathrm{mm}^{-1}\right)$ : (a) tangential bond stress $\left(1.064 \times 10^{-4}\right)$; (b) tangential bond stress $\left(1.069 \times 10^{-4}\right)$;

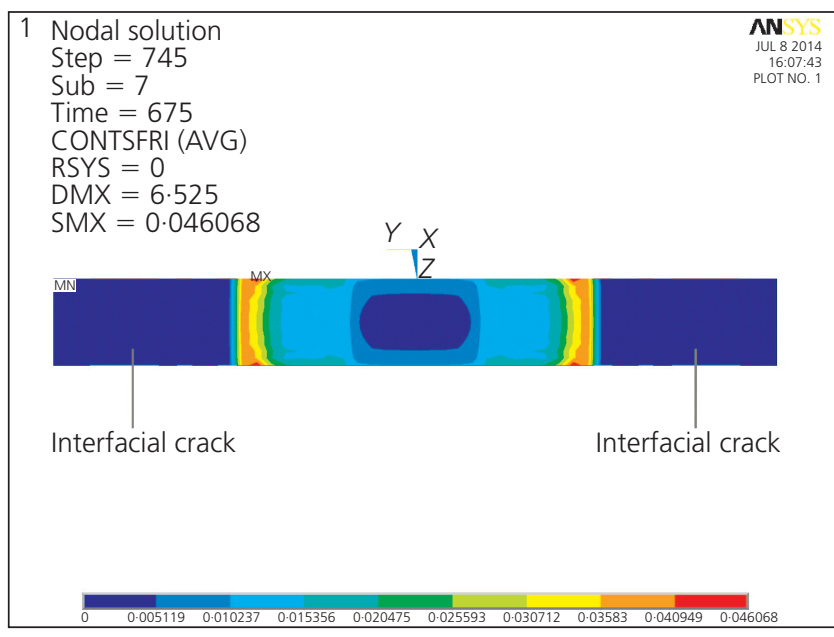

(b)

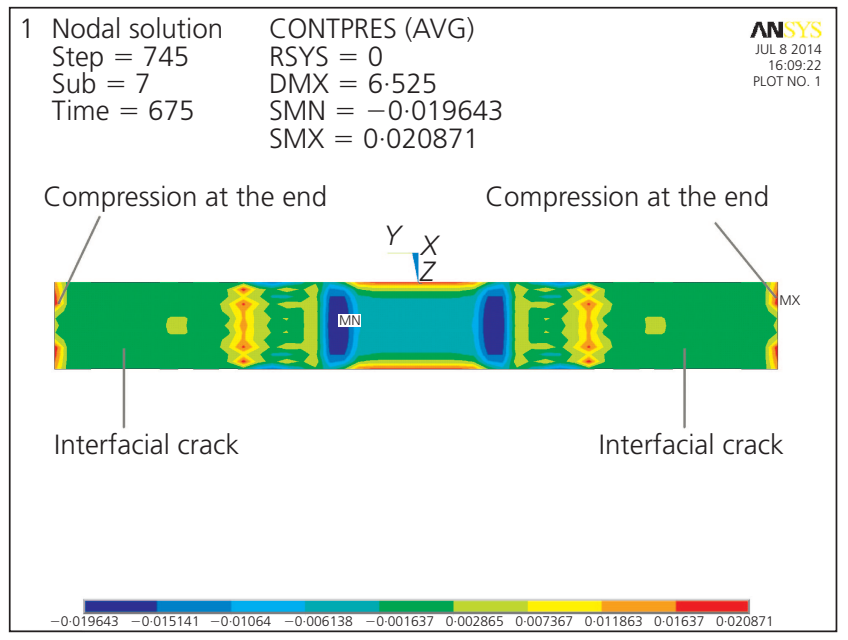

(d)

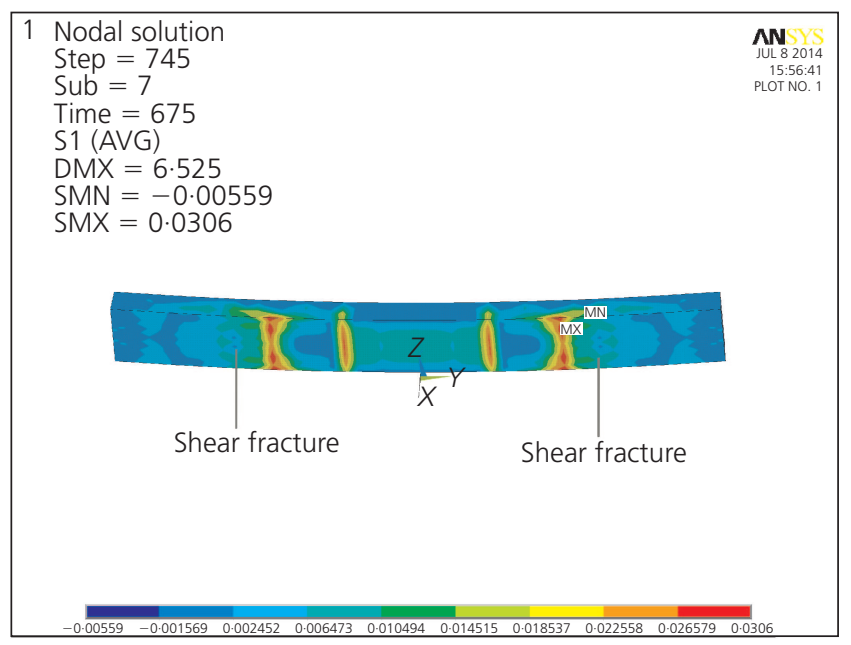

(f)

(c) normal bond stress $\left(1.064 \times 10^{-4}\right)$; (d) normal bond stress $\left(1.069 \times 10^{-4}\right)$; (e) first principal stress $\left(1.064 \times 10^{-4}\right)$; (f) first principal stress $\left(1.069 \times 10^{-4}\right)$ 


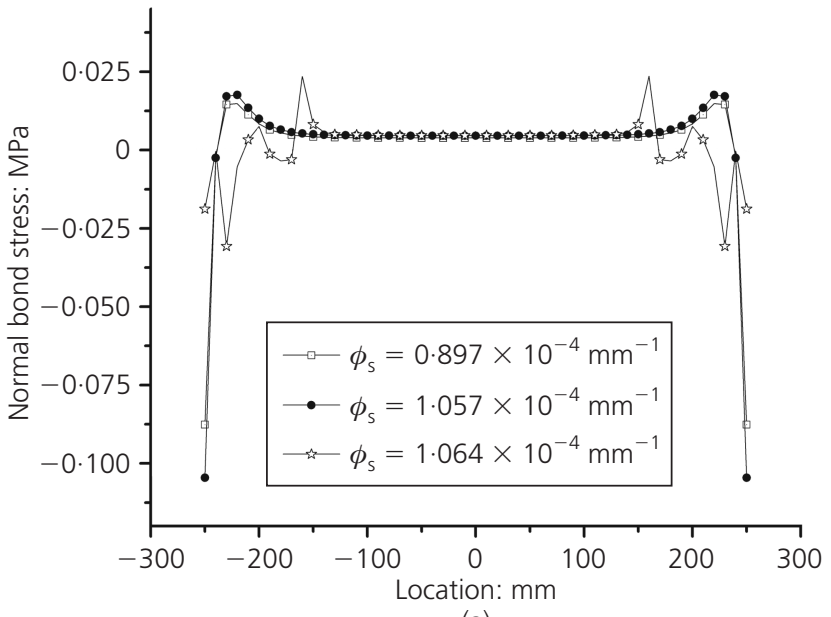

(a)

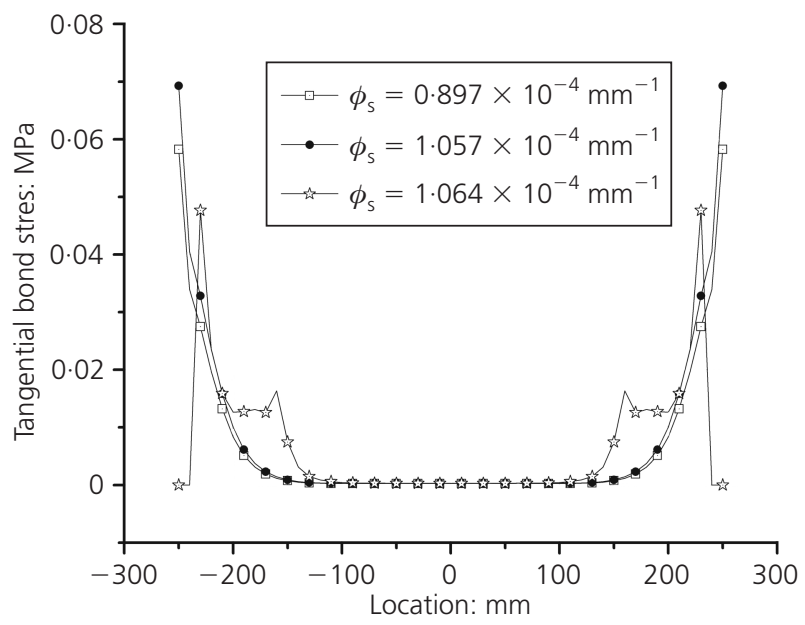

(b)

Figure 13. Bond stress distribution along the axis at different steel curvature on compression side (a) normal direction; (b) tangential direction different thicknesses are compared in Table 5 for the tension side and compression side. The damage mechanisms found for different thicknesses and lengths of coatings on the tension and compression side are shown in Figure 14 and Figure 15, respectively.

From Table 5 and Figures 14 and 15, it is noted that increasing the coating thickness causes an earlier (at lower curvatures) occurrence of interfacial and transverse cracks, and an earlier failure, as well as the change of the damage mechanism. The earlier occurrence of cracking can also be observed in Figure 16. The key reason for this is that increasing the coating thickness increases the bond stresses (both normal and tangential). From Figures 16(a) and 16(b), the 40-mm-thick coating already has an interfacial crack at both ends, at curvatures for which no cracks occur for $20 \mathrm{~mm}$ and $30 \mathrm{~mm}$ coating thicknesses. The damage mechanism may also change with thickness. In the 20-mm- and 30 -mm-thick coatings on the tension side, transverse cracks are observed. But there are no transverse cracks for the 40-mm-thick coating. For the $20-\mathrm{mm}$-thick coating on the compression side, through-thickness shear fractures occur due to the effect of curvature. Nevertheless, no through-thickness shear fracture is observed for cases of $30 \mathrm{~mm}$ and $40 \mathrm{~mm}$. The effect of thickness has also been observed in tests (Figure 2, Table 1).

The length of coating does not have a significant effect on damage propagation and the damage mechanism if it is sufficiently long for shear transfer.

\section{Conclusion}

Monotonically loaded beam bending tests and numerical simulations have been conducted for investigating the damage mechanisms in cementitious coatings for steel members in bending. The influence of coating size has also been studied. The main findings from this work are listed as follows.

(a) For the coating on the tension side, damage initiates from the interfacial cracks at both ends, followed by transverse cracks within the coating. The final failure mode is that the coating

\begin{tabular}{|c|c|c|c|c|c|}
\hline Thickness and length of coating & 20,500 & 30,500 & 40,500 & 20,300 & 20,700 \\
\hline $\begin{array}{l}\text { Curvature for first interfacial crack on } \\
\text { tension side: } \times 10^{-4} \mathrm{~mm}^{-1}\end{array}$ & 0.39 & 0.31 & 0.22 & 0.40 & 0.39 \\
\hline $\begin{array}{l}\text { Curvature for first transverse crack on } \\
\text { tension side: } \times 10^{-4} \mathrm{~mm}^{-1}\end{array}$ & 0.42 & $0 \cdot 32$ & - & 0.42 & 0.42 \\
\hline $\begin{array}{l}\text { Curvature for first interfacial crack on } \\
\text { compression side: } \times 10^{-4} \mathrm{~mm}^{-1}\end{array}$ & 1.063 & 0.878 & 0.683 & 1.068 & 1.075 \\
\hline $\begin{array}{l}\text { Curvature for final failure status on } \\
\text { compression side: } \times 10^{-4} \mathrm{~mm}^{-1}\end{array}$ & $1 \cdot 112$ & 0.880 & 0.687 & 1.071 & 1.096 \\
\hline Shear fracture on compression side & $\begin{array}{l}\text { Through } \\
\text { thickness }\end{array}$ & $\begin{array}{l}\text { Not through } \\
\text { thickness }\end{array}$ & $\begin{array}{l}\text { Not through } \\
\text { thickness }\end{array}$ & $\begin{array}{l}\text { Not through } \\
\text { thickness }\end{array}$ & $\begin{array}{l}\text { Through } \\
\text { thickness }\end{array}$ \\
\hline
\end{tabular}

Table 5. Comparison of damage propagation of different cases 

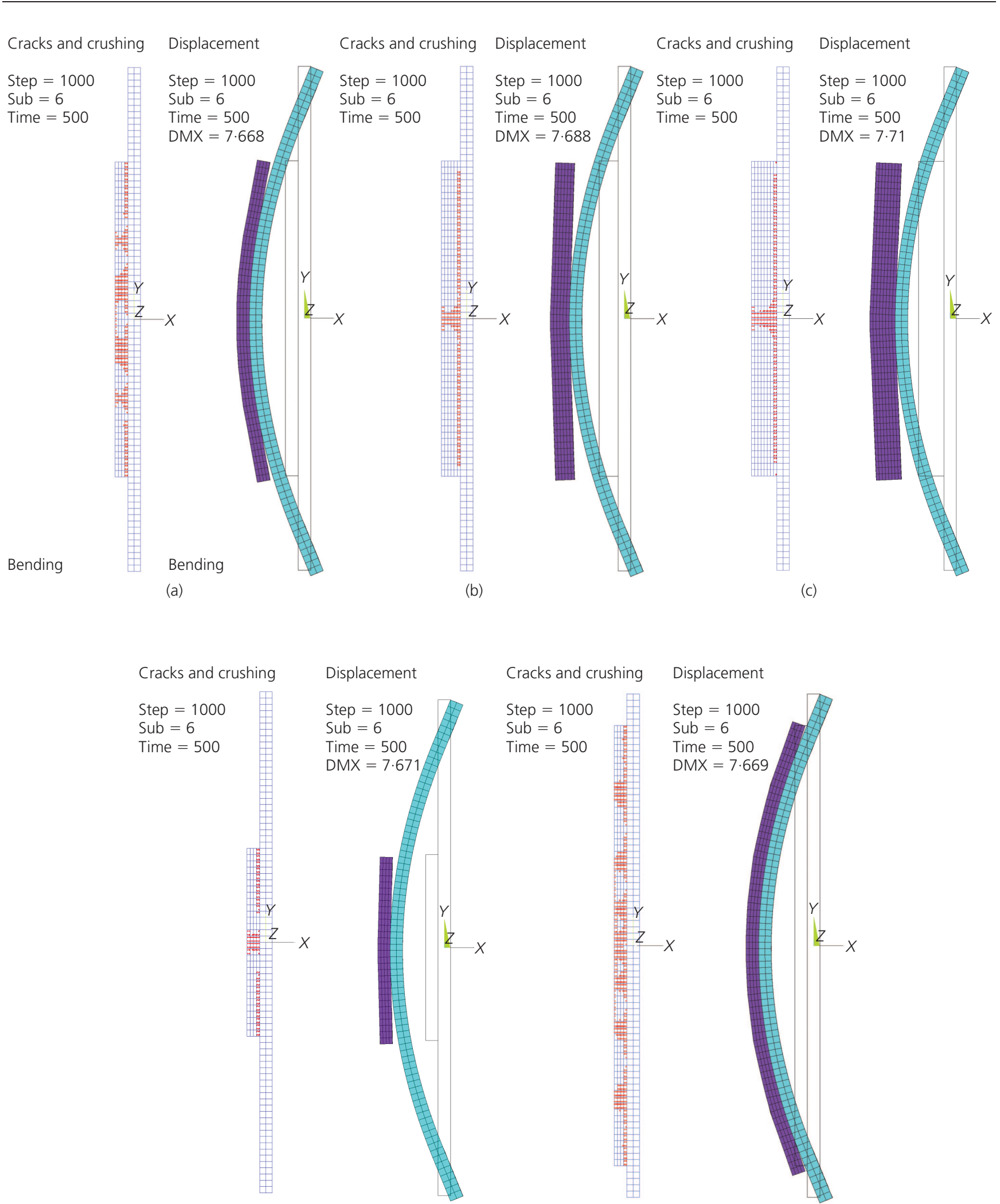

(d)

(e)

Figure 14. Comparison of damage mechanisms and final deformed shapes of different cases on tension side:

(a) $500 \times 60 \times 20$; (b) $500 \times 60 \times 30$; (c) $500 \times 60 \times 40$;

(d) $300 \times 60 \times 20$; (e) $700 \times 60 \times 20$ 
fractures into several segments with delamination at the two ends.

(b) For the coating on the compression side, the damage also starts from the interfacial cracks at the ends and quickly propagates to the centre. The final failure mode is the delamination of the coating and possible shear fractures at both ends.

(c) The effect of curvature is found to have a significant influence on the damage mechanisms found in coatings on steel members in bending, compared to axially loaded members, resulting in more severe damage.

(d) Coating thickness significantly affects the damage mechanism. The thicker the coating is, the earlier the crack occurs. For 40-mm-thick coating on the tension side, no transverse cracks are observed. No through-thickness shear fracture occurs for 30-mm-thick coating and 40-mm-thick coating on the compression side. This finding is useful for proposing solutions to reduce the damage to coating. For 


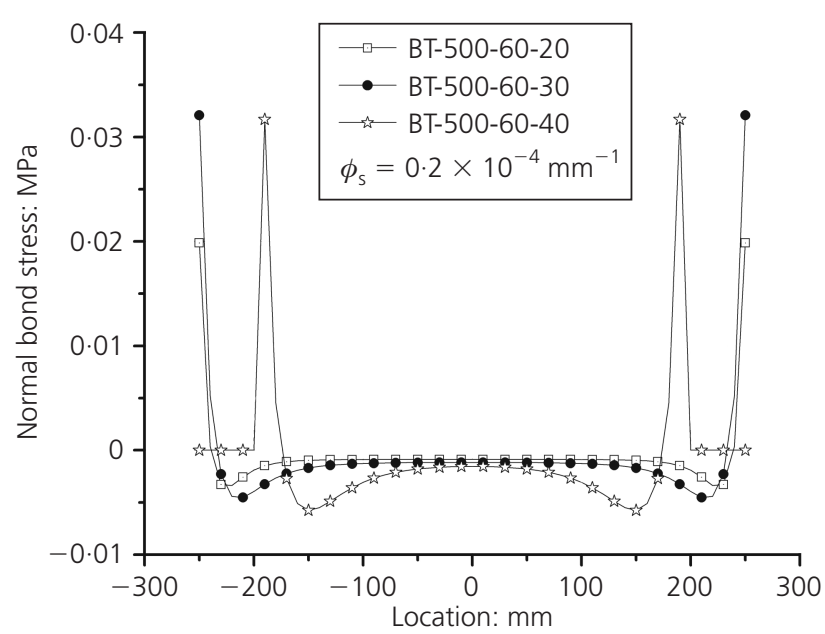

(a)

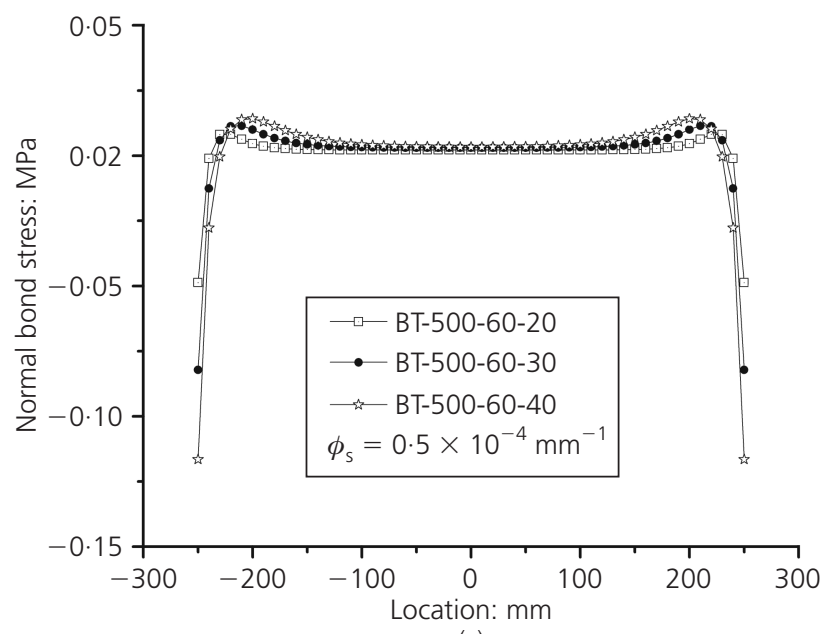

(c)

Figure 16. Stress distribution along axis for different thicknesses: (a) normal bond stress for coating on tension side; (b) tangential bond stress on tension side; (c) normal bond stress for coating on compression side; (d) tangential bond stress on compression side

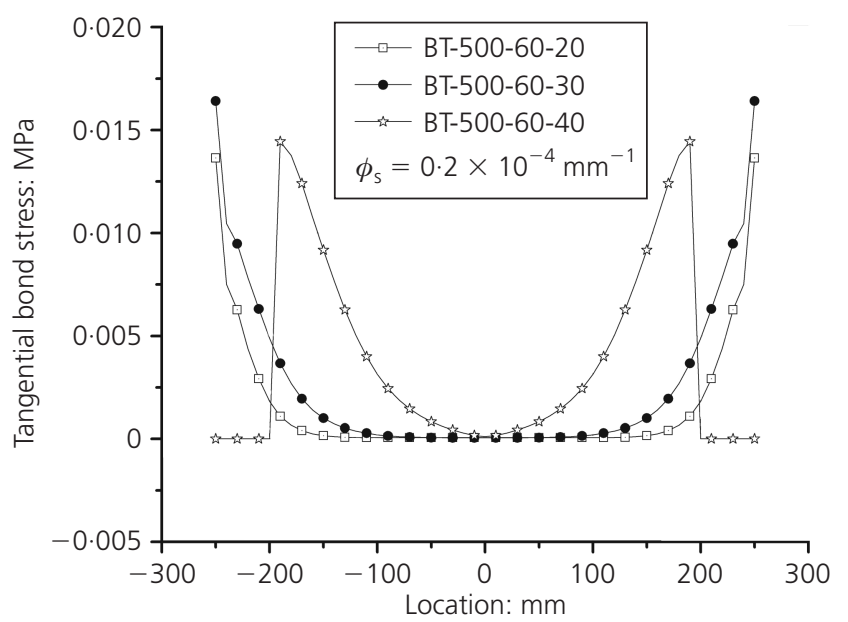

(b)

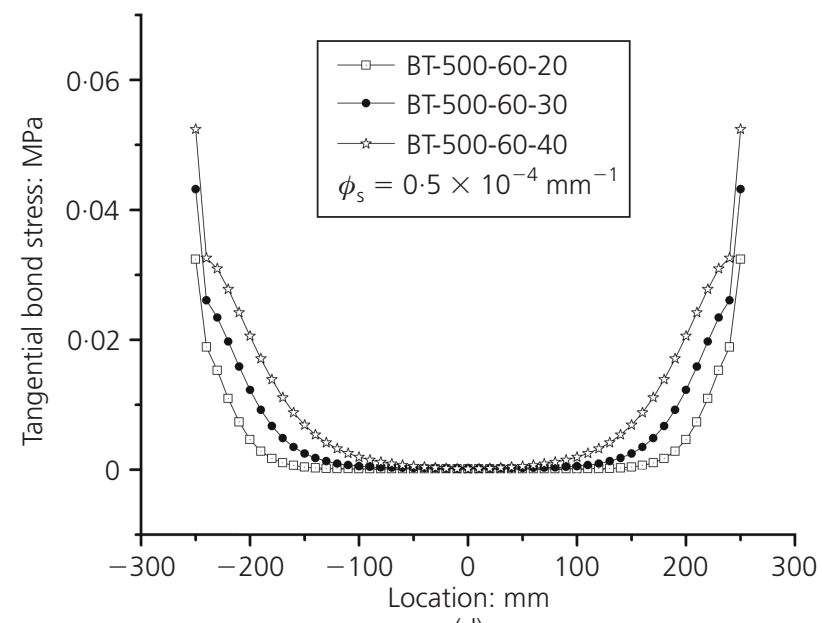

(d) example, the requirement of installing steel mesh when the thickness is larger than $40 \mathrm{~mm}$ according to Chinese code GB14907-2002 (CNS, 2002) may be helpful.

(e) The length of coating does not have an obvious effect on the damage propagation if it is sufficiently long for shear transfer at the interface.

This paper, along with the previous work that it builds on, provides a basis for developing an assessment method to determine the condition of cementitious coatings in real structures under a variety of loading conditions. However, the aim of this research has so far been to understand and quantify the nature of the failures under relatively simple monotonic and quasi-static loading leading to simple stress states (axial compression, axial tension and flexural). As this does not represent realistic loading conditions in a real building, further work needs to be done to establish how the basic failure mechanisms of cementitious coatings identified so far manifest themselves when the coatings are subjected to cyclic and dynamic loading with possible torsional components and correspondingly complex stress states. Furthermore, a great deal of variability in the properties of cementitious coatings has been observed in the experiments, which points to the desirability of a probabilistic framework for using these data as a basis for a methodology to determine damage magnitudes under realistic loading conditions. The authors are currently working on such a framework.

\section{Acknowledgements}

The authors would like to thank former students, Mr Zhao Sheng, Mr Zhang Zhi-Ling, Mr Dong Zhao-Hai and Mr Wu Lin-Sen, and technical staff in the Laboratory in College of Civil Engineering in Tongji University, for their help with experiments. Financial support from the Natural Science Foundation of China 
(grant no. 50808143) and key innovative research project of Shanghai Municipal Education Commission (grant no. 09ZZ37) for this study is gratefully acknowledged.

\section{REFERENCES}

Alfano G and Crisfield MA (2001) Finite element interface models for the delamination analysis of laminated composites: mechanical and computational issues. International Journal for Numerical Methods in Engineering 50(7): 1701-1736.

Braxtan NL and Pessiki S (2011) Bond performance of SFRM on steel plates subjected to tensile yielding. Journal of Fire Protection Engineering 21(1): 37-55.

Chen SW, Jin C and Li GQ (2010) A study on damage mechanism of thick fireproof coating for steel member subjected to monotonic loading. Proceedings of the 6th International Conference on Structures in Fire, East Lansing, MI, USA, pp. 130-138.

Chen SW, Jiang L and Li GQ (2012a) Experimental and numerical damage mechanism investigation of thick fireproof coatings for steel members subjected to monotonic loading. Proceedings of Behaviour of Steel Structures in Seismic Areas, STESSA 2012, Santiago, Chile, pp. 967-972.

Chen SW, Jiang LM, Usmani AS and Li GQ (2012b) A numerical approach for damage simulation of spray-spplied fire-resisting materials on the axially loaded steel members. Proceedings of the 1st International Conference on Performance-based and Life-cycle Structural Engineering (PLSE 2012), Hong Kong, China, pp. 528-537.

CNS (Chinese National Standards) (2002) GB14907: Fire resistive coating for steel structure (in Chinese). Chinese National Standards, Beijing, People's Republic of China.

Dwaikat M and Kodur V (2011) Modeling fracture and delamination of spray-applied fire-resisting materials under static and impact loads. Journal of Engineering Mechanics 137(12): 901-910.

Jiang LM (2012) Numerical Simulation and Study on the Damage of the Thick Fireproof Coating for Steel Member under Monotonic Loading. MSc thesis, College of Civil
Engineering, Tongji University, People's Republic of China (in Chinese).

Jin C (2011) Research on the Failure Mode and Damage Mechanism of the Thick Fireproof Coating for Steel Member under Monotonic Loading. MSc thesis, College of Civil Engineering, Tongji University, People's Republic of China (in Chinese).

Keller WJ and Pessiki S (2012) Effect of earthquake-induced damage to spray-applied fire-resistive insulation on the response of steel moment-frame beam-column connection during fire exposure. Journal of Fire Protection Engineering 22(4): 271-299.

Milke JA, Ryder N and Wolin S (2003) Analyses of the impact of loss of spray-applied fire protection on the fire resistance of steel columns. Proceedings of the 7th International Symposium on Fire Safety Science, Worcester, MA, USA, pp. 1025-1036.

Ryder NL, Wolin SD and Milke JA (2002) An investigation of the reduction in fire resistance of steel columns caused by loss of spray-applied fire protection. Journal of Fire Protection Engineering 12(1): 31-44.

Tan KT, White CC and Hunston DL (2011) An adhesion test method for spray-applied fire resistive materials. Fire and Materials 35(4): 245-259.

Turon A, Dávila CG, Camanho PP and Costa J (2007) An engineering solution for mesh size effects in the simulation of delamination using cohesive zone models. Engineering Fracture Mechanics 74(10): 1665-1682.

Wang WY (2008) Damage Mechanism of Fire Protection on Steel Columns under Earthquake and Influence of Damage on the Fire. PhD thesis, College of Civil Engineering, Tongji University, People's Republic of China (in Chinese).

Wang WY and Li GQ (2009) Behavior of steel columns in a fire with partial damage to fire protection. Journal of Constructional Steel Research 65(6): 1392-1400.

William KJ (1974) Constitutive model for the triaxial behaviour of concrete. IABSE Reports on Working Commissions 19: III-1-III-30.

\section{WHAT DO YOU THINK?}

To discuss this paper, please email up to 500 words to the editor at journals@ice.org.uk. Your contribution will be forwarded to the author(s) for a reply and, if considered appropriate by the editorial panel, will be published as a discussion in a future issue of the journal.

Proceedings journals rely entirely on contributions sent in by civil engineering professionals, academics and students. Papers should be 2000-5000 words long (briefing papers should be 1000-2000 words long), with adequate illustrations and references. You can submit your paper online via www.icevirtuallibrary.com/content/journals, where you will also find detailed author guidelines. 